\title{
Habit and Intention in Everyday Life: The Multiple Processes by Which Past Behavior Predicts Future Behavior
}

\author{
Judith A. Ouellette \\ State University of New York College at Cortland
}

\author{
Wendy Wood \\ Texas A\&M University
}

\begin{abstract}
Past behavior guides future responses through 2 processes. Well-practiced behaviors in constant contexts recur because the processing that initiates and controls their performance becomes automatic. Frequency of past behavior then reflects habit strength and has a direct effect on future performance. Alternately, when behaviors are not well learned or when they are performed in unstable or difficult contexts, conscious decision making is likely to be necessary to initiate and carry out the behavior. Under these conditions, past behavior (along with attitudes and subjective norms) may contribute to intentions, and behavior is guided by intentions. These relations between past behavior and future behavior are substantiated in a meta-analytic synthesis of prior research on behavior prediction and in a primary research investigation.
\end{abstract}

In everyday explanations of behavior, habits denote one's customary ways of behaving. Claiming that one performed a behavior because of habit provides an understandable explanation for an act that otherwise might seem irrational or even harmful. Habits also are featured in the popular psychology literature in the form of self-help books designed to identify readers' existing habits, evaluate habits' effectiveness in meeting goals, and establish more desirable habits. Habits are not, however, important constructs in most contemporary social psychological models of human behavior.

Early in their careers, most psychology graduate students learn that frequency of past behavior, a standard indicator of habit strength (Triandis, 1977, 1980), is the best predictor of future behavior. This truism is typically paired, however, with the caveat that the past-behavior-future-behavior relationship is not especially meaningful. According to one version of the argument, past behavior is simply a proxy variable for a multitude of psychological factors that generate consistency in response. Among the constructs that might be represented by past behavior is attitude toward the action, and any link between past behavior and future behavior might be due to this evaluative disposition. Past behavior has been discounted also because of the supposed limited explanatory value of behavioral repeti-

Preparation of this article was supported by Grant SBR-9514537 from the National Science Foundation. We thank Shannon Steadman and Lindsey Melton for assistance with the collection and coding of articles; Bill Sribney for his statistical advice; and Icek Aizen, John Bargh, Brad Bushman, Blair Johnson, Gregory Pool, Radmila Prislin, and Bas Verplanken for their very helpful comments on a draft of this article.

Correspondence concerning this article should be addressed to Judith A. Ouellette, Department of Psychology, State University of New York College at Cortland, Cortland, New York 13045, or to Wendy Wood, Department of Psychology, Texas A\&M University, College Station, Texas 77845. Electronic mail may be sent to jao@cortland.edu or to wlw@psyc.tamu.edu. tions. In this view, the relation between past and future acts represents little more than temporal stability. To illustrate this point, Ajzen (1987) argued that it is not particularly illuminating to say that a person is on time for appointments because he or she has a tendency to be punctual. The definition of punctuality is being on time. He concluded that "it serves no useful purpose to include past behavior . . . in causal models of human action" (p. 41 , italics in original). ${ }^{1}$

These questions about the meaningfulness of past behavior have excluded it from much of the empirical research predicting future responses and have discouraged the development of theoretical explanations for past behavior effects. We believe, however, that it is useful to reconsider the role of past behavior. The most compelling reason is the reputed success of past behavior as a predictor of future acts. Researchers have not attained such success at predicting behavior as to be able to dismiss this (presumed) relation as error variance. Furthermore, the study of established behavior patterns provides unique insight into the prediction and control of behavior in a number of everyday life domains, especially health-related behavior (e.g., medical compliance, exercise). For practitioners interested in changing habitual behaviors, successful intervention strategies depend on understanding the factors that maintain routinized responses.

The present article draws on research in automaticity and action initiation to identify the mechanisms through which past behavior is linked to future behavior. In brief, we suggest that multiple processes are involved. In domains in which habits can develop, frequent performance in the past reflects habitual patterns that are likely to be repeated automatically in future responses. In domains in which habits are unlikely to develop, behavior is likely to be controlled by deliberative reasoning

\footnotetext{
${ }^{1}$ It is worth noting that Ajzen (1985) also recognized a role for habitual responses in predicting behavior within rational reasoning models. He suggested that, when a goal has both attractive and repulsive features, people's conflicting behavioral tendencies may be resolved in favor of more routinized responses and familiar response patterns.
} 
processes, and the effects of past behavior on future behavior are mediated by intentions. These ideas were evaluated with a meta-analytic synthesis of prior research as well as with primary data.

\section{Habits and Automaticity}

We begin with a relatively bare-bones definition of habits as behavioral tendencies. They are tendencies to repeat responses given a stable supporting context. These patterns of response probably develop in the same way as any skill acquisition. With repetition and practice of a skill in a given setting, the cognitive processing that initiates and controls the response becomes automatic and can be performed quickly in parallel with other activities and with allocation of minimal focal attention (Posner \& Snyder, 1975; Schneider \& Shiffrin, 1977; Shiffrin \& Schneider, 1977). Automatic responses also can represent nonvolitional, frequent, and consistent experiences in a given context (see Wegner \& Bargh's [1998] analysis of nonconscious perceptual categorization). In contrast, the initiation and execution of nonroutine responses or responses in novel contexts require controlled processing, which is relatively slow, serial, and limited by the capacity of short-term memory.

Automatic processing is closely dependent on stimulus constancy. Although no situation ever completely maps onto earlier experiences, repeated response sequences proceed quickly without limiting processing capacity to the extent that the supporting features of the current environment are similar to those contexts in which the behavior was learned and practiced in the past. The question of how much constancy is required has been addressed in some detail in research on transfer of learning (e.g., Heuer \& Schmidt, 1988; Proctor \& Dutta, 1993), and we note here only that habitual responses are likely to occur with minimal thought and effort to the extent that the contextual features integral to performing the response and one's behavioral goals are similar across time and setting. Thus, stable contexts may vary in superficial attributes, but they provide a constant supporting environment for performance. Unstable contexts are ones in which shifts in the supporting environment present new goals or challenge the smooth initiation and execution of practiced responses.

Although there is general agreement that habitual responses are automatic in the sense that they can be performed quickly in parallel with other activities and with allocation of minimal attention, some earlier discussions of habit (e.g., Ronis, Yates, \& Kirscht, 1989) erroneously concluded that habits are thus nonvolitional and unintentional. Automatic behaviors can be nonvolitional or can be performed as part of volitional and intentional action systems (Bargh, 1989, 1994; Logan, 1989; Posner \& Rothbart, 1989; Wegner \& Bargh, 1998). Indeed, many established behavioral routines in daily life can be characterized as both volitional and automatic (e.g., driving, exercise).

\section{Intentions for Habitual Behavior}

The idea that habits can be part of intentional behavior systems may seem counterintuitive. In phenomenological experience, habitual behaviors unfold in response to environmental events, often without the formulation of any conscious intent to engage in a specific sequence of action. For example, when answering a telephone, few people consciously form an intention about which hand to use when lifting the receiver, what to say, or what intonation to use when delivering the standard greeting.

Well-practiced activities in constant contexts may appear to the actor to be unintentional and nonvolitional for several reasons. The relevant intentions may not be accessible to conscious awareness (Bargh, 1994; Bargh \& Gollwitzer, 1994; Verplanken, Aarts, van Knippenberg, \& van Knippenberg, 1994). Although, in the initial stages of acquiring a skill and performing a behavior, intentions may be consciously and deliberately formed in response to environmental events, with repetition in constant contexts, they may (like behaviors) operate autonomously with minimal conscious guidance. As Heckhausen and Beckmann (1990) argued, "intents resemble plans about how to act when predetermined cues or conditions occur. Once formed, however, the intents no longer require much conscious control. Instead, they are triggered as automatic or quasi-automatic operations" (p. 38).

Another reason that specific intentions are not likely to be accessible for well-practiced behavior is that, with practice, intentions come to be framed in general rather than specific terms (Heckhausen \& Beckmann, 1990). When learning a behavior or when performing a practiced behavior in difficult or unpredictable contexts, intentions include details of how to initiate, implement, and terminate the action; these specifics are useful in decision making about performance. Thus, children learning to use the telephone formulate specific, short-term intentions, such as holding the receiver close to the ear. With practice in constant contexts, intentions tend to be represented in a broader, more efficient manner. They reflect more stable, longer term, and goal-directed strategies that highlight the functions of the act or the goals that will be met by the action (Heckhausen \& Beckmann, 1990; Vallacher \& Kaufman, 1996; Vallacher \& Wegner, 1987). In our example, answering the telephone is then likely to be framed in terms of broad goals that specify why the action is performed and what its effects are likely to be: stopping the annoying ringing, identifying the caller and intended recipient, and potentially initiating a conversation. Well-practiced skills may thus possess the same functional transparency to the actor as well-designed machinery does for the operator (Vera \& Simon, 1993); the functions served by the action become salient, whereas the detailed mechanics (i.e., for skills, the specific behaviors, and corresponding intentions) through which the outcomes are achieved become transparent.

Another related reason that intentions are not highly accessible for practiced acts is that, as behaviors are repeated in daily life, separate responses and the intentions controlling them are likely to be chunked into large, efficient units that include multiple behaviors. These action sequences may have automatic and controlled components. The typical course of such semiautomatic response patterns is a string of autonomous phases, with each phase running to completion once initiated. In between the phases, some act of control is required, either to initiate the next phase or to stop the process (Bargh, 1989). The duration of autonomous processing phases in mental and motor tasks appears to be quite short, about half a second or less (Logan \& Cowan, 1984), and then some amount of conscious monitoring 
or direction is presumably required. Some researchers (e.g., Pashler, 1994) have questioned whether any acts can be truly independent of attention. Even the well-practiced sequences in routinized behaviors may not be truly automatic; they may appear to function independently of attention because, with practice in constant contexts, tasks can be prepared and executed quickly, and whole sequences of responses may be selected and loaded at the same time. Thus, for example, a standard greeting between bus driver and passenger at the end of a workday can be smoothly enacted while both continue uninterrupted contemplation of their evening plans.

In sum, in constant contexts, well-practiced behaviors are repeated because of the speed and ease with which such responses can be performed. Performance of habitual behaviors does not, however, require conscious intention.

\section{Conscious Intentions and Behavior}

Intentions also can direct behavior consciously through controlled reasoning processes. Rational reasoning models of action outline how responses are guided by conscious intentions, which represent plans of action in pursuit of behavioral goals (Ajzen, 1987, 1991; Fishbein \& Ajzen, 1975; Triandis, 1977, 1980). Intentions are formed from salient beliefs about the outcomes of an act. To be specific, intentions reflect attitude toward the behavior, defined as the favorability of the consequences of an act and the importance of these effects. From this perspective, attitudes are linked to behavior through their effect on behavioral intentions (see also Eagly \& Chaiken, 1993). Intentions also reflect subjective norms (i.e., beliefs about others' wishes as well as one's motivation to comply) and perceived control (i.e., beliefs about how difficult it is to perform the behavior; Ajzen, 1987, 1991).

The kind of reasoning that people engage in when consciously deliberating about intentions depends on their level of motivation and their ability and opportunity. Establishing intentions may involve only minimal effort and superficial thought, as when people retrieve intentions from memory or form intentions from some heuristic cue such as others' judgments. Alternately, intentions may be formed through more extensive, thoughtful, systematic analysis (Eagly \& Chaiken, 1993). Implementation of intentions may similarly involve minimal or substantial effort and ability, depending on factors such as the difficulty of the behavior and how easy it is to anticipate changes in the environment.

In summary, we suggest that action generation and control can follow two processes: (a) automatic repetition of past acts and (b) controlled, conscious reliance on behavioral intentions.

\section{Correspondence Between Habits and Conscious Intentions}

Intentions sometimes conflict with habits. A shift in the perceived consequences of behavior or in one's evaluation of those consequences can motivate people to form new intentions. For example, conscious intentions counter habitual patterns when people attempt to change bad habits. Bad habits represent unproductive or undesirable behaviors that are well practiced and proceed relatively automatically with minimal effort and guid- ance. Bad habits may arise when acts yield outcomes that were valued in the past but are not so any longer. Bad habits also may represent acts that yield short-term rewards that are inconsistent with long-term intentions and goals. Alternatively, these behavior patterns may have developed as side effects of other intended acts, or it may be that behavioral tendencies that are not especially valued in themselves (e.g., making a breakfast of donuts from the office vending machine) were practiced because they were easy, efficient, and preferable to expending the time and energy to establish more highly valued (e.g., healthier) alternatives.

Conscious intents also may correspond to habits. When people are asked about their future behavior, either by interaction partners in everyday settings or as participants in psychological research, their responses express intent. Except when intents are formed specifically to counter established responses (e.g., to change bad habits), we suspect that intents typically are positively correlated with habits. This is because people are likely to form favorable intentions about acts they have frequently performed in the past. In the absence of extrinsic constraints on behavior, people are likely to infer that they intended to perform repeated acts and, because of cognitive consistency pressures or through a self-perception process, they may generate consistent intentions for future responses (Bem, 1972; Festinger, 1957).

Therefore, when people deliberately form conscious intentions, past behavior is likely to be a contributing factor. Past behavior frequency might combine with the other predictors specified in logical reasoning models, including attitudes toward the behavior, perceived social pressure, and apparent ease of performing the behavior (Ajzen, 1991). Others have speculated that past behavior is indirectly related to intents through its effects on these other predictors. For example, frequent past behavior might be used to infer a favorable attitude toward the behavior (Eagly \& Chaiken, 1993), and intentions are then derived from attitudes based on past behavior. In addition, past behavior frequency might inform judgments of perceived control such that high-frequency acts are judged under one's control. These control beliefs might then affect intents (Ajzen, 1987).

In summary, the two modes of action generation and action control, that is, automatic repetition of past acts and conscious deliberation, represent two potential routes through which past behavior affects future behavior. Frequency of past behavior can affect future behavior directly, through automatic repetition of previously established routines, or indirectly, mediated through conscious intents to behave (cf. Eagly \& Chaiken, 1993).

\section{Habits and Intentions Jointly Predict Action}

Given that action can emerge through both conscious and nonconscious processing, people will sometimes have multiple potential guides to action (for general discussions of this point, see Bandura, 1986; Carver \& Scheier, 1990; Hay \& Jacoby, 1996; Heckhausen \& Beckmann, 1990). How do habits and conscious intents combine in the prediction of behavior?

Habits are enacted in parallel with other modes of behavior regulation; they represent a default or baseline response. Habitual behavior is triggered by environmental events, and its performance requires minimal attention and deliberate control. Thus, 
in contexts that encourage the development of habits, habits are likely to be potent predictors of future responses.

When people's conscious intentions correspond to their habitual behavior, actions are likely to be cued directly by recurring features of the environment and to be relatively automatic. When intentions oppose habitual behavior, responses are likely to be directed by intentions only insofar as intentions are powerful enough to override the existing habits. New intentions need to be held with sufficient strength and implemented with sufficient skill to override well-practiced behavior. Continued control over performance is necessary until the new response is established with greater potency than existing habits. The continued effort required to shift well-established behavior patterns is exemplified in the adage for weight control that "the price of thinness is constant vigilance."

Overriding a habit is difficult for information processing as well as for motivational reasons. Regardless of one's motivation and opportunity to enact new intentions, suppression of established behavior may be sidetracked by "ironic" thought processes that bring to mind information relevant to suppressed acts (Wegner, 1992). Thus, smokers who wish to quit may find that their conscious decision not to smoke requires them to think often about (not) smoking and so increases their preoccupation with cigarettes.

In contrast, in contexts in which habits are not well established, either because the behavior is new or because the performance context is difficult or unstable, behavior is likely to be guided by conscious, controlled processes. It may seem obvious that habits do not guide behavior in contexts in which they are not available. In addition, however, shifts in supporting context and the presence of unanticipated difficulties mute the impact of the habits that are available. When past behavior cannot be implemented in an automatic fashion, conscious deliberation yields responses that are tailored to specific features of the context. These behaviors may diverge from established patterns even given stability in one's overall goals (e.g., the office vending machine that is out of donuts might spur a trip to a cafe and a healthier breakfast rather than to a machine in a neighboring building). The supremacy of controlled processing in such cases is an adaptive solution that allows flexible shifts in behavior that are tailored to special circumstances that differ from those encountered in the past (Wegner \& Bargh, 1998). ${ }^{2}$

The general idea that behavior can be controlled through conscious and nonconscious processing is compatible with previous theorizing about the multiple processes by which attitudes direct behavior (Ajzen, 1996; Bargh, Chaiken, Grovender, \& Pratto, 1992; Fazio, 1990). As with these attitude models, we assume that, when people are motivated and able, they systematically form conscious intentions to act, which are based on a variety of dispositions, including attitudes and, we posit, frequency of past behavior. The nonconscious mechanisms specified in attitude models, however, differ from the present approach. Automatic mechanisms in these models refer to unintentional, spontaneous effects of attitudes on conscious thought. For example, Fazio has argued that attitudes accessible in memory can automatically bias conscious perceptions of the attitude object and surrounding context and that these perceptions then direct behavior. Although we recognize these nonconscious influences on thought, we propose that repetition of practiced behavior in stable contexts can proceed with only minimal or sporadic cognitive processing. Therefore, habit performance does not involve any particular perceptions of the behavior and the surrounding environment. ${ }^{3}$

\section{Habit and Related Constructs}

The present analysis of habit builds on an extensive past literature. William James (1890) was an early proponent of the habit construct; he suggested that habits possess motivational properties, provide continuity to experience and behavior, and maintain social structure. "Habit is thus the enormous flywheel of society, its most precious conservative agent. It alone is what keeps us all within the bound of ordinance, and saves the children of fortune from the envious uprisings of the poor' (James, 1890 , p. 121). Early sociologists also recognized the usefulness of the concept of habit and invoked it to account for the stability of social institutions (Durkheim, 1902/1964; Mead, 1936; Weber, 1915/1946).

In psychology, habit assumed a prominent role in learning theory accounts of social behavior. Habit was linked to conditioned response (F. H. Allport, 1924; Watson, 1919), and the concept of habit-based family hierarchies was used to account for the differential strength of potential responses in a given context (e.g., Miller \& Dollard, 1941; Staats, 1965). In Hull's (1943) stimulus-response theory, habit strength reflected the extent to which a behavior had been reinforced in the past. The role of reinforcement in habit formation is generally congruent with our claim that habits develop as people repeat behaviors that (at least during habit development) meet valued goals.

More recent theoretical analyses have considered habit from an information-processing perspective. In predictive models of health behavior, past behavior is thought to have direct effects on future responses not mediated through conscious intentions and decision making (Hunt, Matarazzo, Weiss, \& Gentry, 1979; Norman \& Conner, 1996; Ronis, Yates, \& Kirscht, 1989; Sutton, 1994). Information-processing perspectives share with the present view the ideas that habits emerge from response repetition and that habits are guided by cognitive processing that is fast, is easy, requires minimal attention, and proceeds in parallel with other activities.

Given the various interpretations of habit in the literature, it

\footnotetext{
${ }^{2}$ Although the present research emphasizes response repetition and context stability as determinants of the interaction between habits and conscious deliberation, other factors are likely contribute to the relative impact of these processes. For example, Triandis (1977) speculated that individual differences are likely in the extent to which people establish and rely on habits versus consciously deliberate about action. Some people may be more likely to repeat past behaviors than others, and some may be more likely to deliberate about future action.

${ }^{3}$ It would be incorrect to conclude that, in important behavioral domains, people engage in conscious monitoring and decision making, whereas for less important, personally relevant behaviors, they follow automatic, habitual patterns. Because automatic processes develop out of frequent and consistent experience with the environment, they emerge from stable goals and recurring experiences. Thus, habits are likely to reflect important constancies in people's lives (see Bargh and Barndollar's [1996] idea of the wise unconscious) in addition to reflecting routine, trivial events.
} 
has been important to distinguish habits from related constructs, especially attitudes. G. W. Allport (1935) suggested that these terms differ in level of abstraction: Attitudes range from the general to the specific, whereas habits are always limited in scope. Allport also noted that habits are not necessarily evaluative; because they lack directedness and favorability, they may be less useful than attitudes in accounting for evaluative responses. Finally, he suggested that although habits are more rigid than attitudes-more specific in their dependence on the stimulus and more invariable in their expression - both dispositions have a conservative effect in maintaining existing response patterns. Similarly, a contemporary definition of attitudes as "a psychological tendency that is expressed by evaluating a particular entity with some degree of favor or disfavor"' (Eagly \& Chaiken, 1993, p. 1) allows for separable attitude and habit constructs and for unique effects of each on behavior. Indeed, Triandis (1977) explicitly argued that the probability of an act is a function of (a) habit (i.e., the number of times the act has been performed in the past), (b) intention to engage in the act (i.e., a composite of affect, attitude, and social factors), and (c) facilitating conditions.

The reader should note several additional constructs that can be distinguished from habit. Scripts are knowledge structures representing predetermined, stereotyped sequences of actions in well-known situations (Schank \& Abelson, 1977). Scripts supposedly facilitate interpretation: They fill in gaps of missing information, provide connectivity to pieces of information or events, and allow prediction and anticipation of subsequent events. Abelson (1981) suggested that "the difference between a script and a habit is that a script is a knowledge structure, not just a response program"' (p. 722). In addition, Langer (1989a, $1989 \mathrm{~b}$ ) cautioned against equating the construct of mindlessness with habits. Although both involve relatively effortless, invariant behavior, habits are more closely linked to behavioral response. In particular, habits derive from repetition of behavior and, instead of reflecting a general mental state of the organism as a whole, represent a specific form of response (Langer, 1989b).

\section{The Present Research}

We conducted a meta-analytic synthesis of existing research to test our ideas about the direct and indirect effects of past behavior on future responses. When behavior has been practiced frequently in constant contexts, it can be performed relatively automatically, and future behavior should be a direct function of past act frequency. When past behavior has not been repeated often or when the context of performance changes or is difficult, then behavior will require (at least minimal) deliberation. Responses are likely to be guided by consciously formed intentions and from the attitudes, subjective norms, and perceptions of control that constitute intentions. In such cases, past behavior has a mediated effect on future responses through its impact on conscious intentions.

We evaluated whether the behaviors in the studies in our review were likely to support the development and performance of habits. To identify whether the behaviors could be performed with sufficient frequency, we classified studies according to whether people have the opportunity to perform the target behavior (a) daily or weekly in the typical person's everyday life (e.g., seat belt use, coffee drinking, exercise) or (b) only annually or a few times a year (e.g., flu shots, blood donation). To identify the stability of critical features of the setting, we classified studies according to whether the target behavior was performed (a) in contexts in which enabling features are likely to be stable (e.g., class attendance at college, church attendance, clipping grocery coupons) or (b) less stable (e.g., nuclear protest behavior, new mothers exercising after childbirth).

Our hypotheses were as follows. Past behavior should have a direct effect on future behavior primarily when people have had ample opportunity to perform the behavior in stable contexts. Thus, past frequency of seat belt use should be a good predictor of future use, given that participants are driving the same car under constant circumstances. Conscious intentions also should be a predictor in these contexts. When people do not perform a behavior frequently despite considerable opportunity, or when people's intentions modify established habits (e.g., the decision to wear seat belts regularly), then intentions are likely to be at least a moderate predictor of future acts.

Behaviors that people have had little opportunity to perform or that occur in shifting or difficult contexts are likely to require conscious decision making and control. In these domains, the effects of past behavior on future behavior are likely to be mediated by conscious intentions (and the attitudes, subjective norms, and perceived control that contribute to intents). Past behavior frequency thus should have an effect to the extent that it contributes to intentions. For example, past blood donation is not likely to have a direct effect on future frequency. Although a person might report that she is a "frequent" blood donor, this behavior can occur only a few times a year and the contextual features surrounding the donation are not likely to be the same every time (given that most donors do not have a regular appointment at a blood donation center). Thus, past donations are unlikely to represent an established habit that repeats into future behavior. Instead, future donations are likely to reflect conscious intentions, and past donation frequency should be important to the extent that it affects the intentions formed. Thus, for lowopportunity behaviors and for behaviors in unstable contexts, we anticipated an indirect relation between past and future behavior, which is mediated by conscious intentions.

In summary, we expected that past behavior would predict future behavior primarily in domains with high opportunity and stable contexts and should have little effect in domains with low opportunity or unstable contexts. Past behavior in domains with low opportunity or unstable contexts should be an indirect predictor of future behavior through its impact on conscious intentions. We were less certain of the relation between conscious intention and future behavior. Given that such moderators of habit effects as opportunity and context stability seem to have little impact on controlled reasoning processes like intention (Hay \& Jacoby, 1996), intention might be expected to have similar effects across domains. Alternately, if habitual behavior is automatically cued and is performed regardless of intention, then intention should have its strongest impact when habits are weak or cannot be executed, that is, in domains with low opportunity or unstable contexts.

How does past behavior contribute to intentions? We suggest above that past behavior can directly inform intentions for future responses through self-perception (Bem, 1972) and cognitive 
consistency processes (Festinger, 1957). Past behavior also can contribute indirectly to intentions by affecting attitudes, perceived normative pressure, and perceived control. That is, the same self-perception and cognitive consistency processes may yield inferences about attitudes, normative pressure, and perceived control that are consistent with frequency of past performance. More frequent past behavior is likely to yield more favorable attitudes, positive perceptions of normative pressure, and greater control (i.e., less difficulty performing the behavior), and these factors might then contribute to favorable intentions. We examined these other predictors of intentions and future behavior in order to identify the independent effects of past behavior after controlling for attitudes, subjective norms, and perceived control. We anticipated that past behavior would predict intentions and future behavior in its own right and not because it forms the basis for favorable or unfavorable attitudes toward the behavior (Eagly \& Chaiken, 1993) or because it affects judgments of perceived control (Ajzen, 1987).

We were able to provide additional insight into the relation between past behavior and intentions by evaluating the way that intention was operationalized in the studies in our review. Some studies measured intentions in terms of participants' expectations for performing a behavior in the future. Given that measures of behavioral expectations represent estimates of typical performance (cf. Warshaw \& Davis, 1985), they are likely to be highly dependent on frequency of past acts. Other studies assessed participants' explicit plans to perform a behavior. Because these behavioral intentions involve explicit planning and goal setting, they may not be as closely dependent on past act frequency as expectation intentions.

We did not anticipate that opportunity to perform an act or context stability would have much effect on the predictors of intention in rational reasoning models. Because opportunity and stability are unlikely to be important determinants of intentional reasoning, the effects of attitudes, norms, and perceived control on intention should not vary with these moderators.

\section{Method}

\section{Identification of Sample}

Computerized literature searches were conducted in PsycLIT (19741994), Sociofile (1974-1994), and Dissertation Abstracts (18671994) with the terms habit and past behavior in conjunction with the terms attitude and behavior. Additionally, nonelectronic searches were conducted in Psychological Abstracts (1920-1973) and the Annotated Subject Index and the Author/Title Index of the Journal of Marketing Research (1986-1993). Articles also were identified from prior reviews (e.g., Sheppard, Hartwick, \& Warshaw, 1988), from bibliographies of research on the theory of reasoned action and theory of planned behavior (Ajzen, 1996; Fishbein \& Ajzen, 1995), and from the reference sections of included articles. Thus, articles and manuscripts that appeared in the literature prior to 1995 were included in the review.

\section{Selection Criteria}

Articles were included in the review if they used measures of past behavior frequency to predict behavioral intention or subsequent behavior. In addition, because we wished to differentiate the effects of past behavior from attitudes, we did not include the few studies that failed to obtain an attitude measure (e.g., Landis, Triandis, \& Adamopoulos,
1978; Valois, Shephard, \& Godin, 1986). In addition, to maximize the prediction of behavior, we restricted the review to those studies in which the measures (i.e., of attitude, intention, past behavior) referenced a common attitude object (see Ajzen and Fishbein's [1977] principle of correspondence). Thus, we did not include the few studies in which the attitude measure assessed an object (e.g., healthy diet) that differed from the intention-behavior measure (e.g., exercise; see Croll, 1983; Kilty \& Behling, 1985). We attempted to apply minimal criteria for exclusion and retained studies even if the measures did not correspond on dimensions of context and time. Finally, studies were excluded if, before data were collected on all measures, participants were exposed to an intervention designed to change their dispositions or behaviors (e.g., Zimmerman, 1983).

We identified 60 separate research reports. The multiple studies in several reports yielded a total of 64 independent studies in the review.

\section{Coding of Studies}

Each study was coded by two independent raters for the following characteristics: (a) operational definition of habit (behavior in the past week to a year, behavior from 3 years to a lifetime, a composite representing weekly frequency multiplied by intensity [see Godin, 1983], or other): (b) number of questionnaire items in the measure of habit; (c) number of questionnaire items in measure of behavior; (d) number of questionnaire items in measure of intentions; (e) wording of intentions measure (behavioral intention vs. behavioral expectation); ( $f$ ) as best as could be ascertained from the procedure section of the methodology, order of assessment of habit and intention measures (past behavior first vs. intention first); (g) the stability of the environmental context in which the behavior was typically performed (stable vs. less stable); (h) opportunity to perform the behavior in daily life (every day, several times a week, or weekly vs. annually or biannually); (i) percentage of female participants; $(j)$ year of publication or study completion; $(k)$ publication status (journal, unpublished manuscript, thesis or dissertation, book chapter, or conference presentation ); (1) amount of physical effort and energy needed to perform the behavior (low, as with seat belt use; moderate, as with participating in organized demonstrations; or high, as with aerobic exercise); and ( $m$ ) whether or not there was a physiological component associated with the target behavior that would plausibly enhance or inhibit its occurrence (e.g., the nicotine ingested from cigarettes would enhance the likelihood of smoking and inhibit the likelihood of quitting). The coding of studies was completed prior to calculating study outcomes. Interrater agreement on each of these dimensions ranged from $81 \%$ to $100 \%$, and disagreements were resolved by discussion. $^{4}$

No interpretable effects were obtained for the following variables: percentage of females in sample, year of study, and publication status of study. Furthermore, too few studies assessed behaviors with a likely physiological component to evaluate the effects of this variable. Finally, the effect of amount of effort to perform the behavior was not especially meaningful; past behavior had weaker relations to intention and to future behavior when behavior performance required moderate effort than when performance required little effort or considerable effort. These predictors are not discussed further.

\footnotetext{
${ }^{4}$ Study characteristics were coded by Judith A. Ouellette and an undergraduate student uninformed of the purposes of the study. To ensure accuracy of the coding for opportunity for performance and context stability, these two study attributes were recoded by two students, both blind to the study hypotheses. The two new coders agreed on $86 \%$ of their judgments. Furthermore, their agreement levels with the original coding were $77 \%$ and $85 \%$ for each coder, respectively. All disagreements were resolved through discussion.
} 


\section{Computation of Effect Sizes}

Effect size estimates were calculated as bivariate correlations ( $r$ ) for those studies that furnished sufficient information. We (the authors) worked independently to calculate effect size estimates for the relations between the following variable pairs: past behavior-intention, past behavior-future behavior, past behavior-attitude, past behavior-perceived control, past behavior-subjective norm, attitude-intention, attitude-future behavior, attitude-subject norm, attitude-perceived control, perceived control-intention, perceived control-future behavior, perceived control-subjective norm, subjective norm-intention, subjective norm-future behavior, and intention-future behavior.

Because most of the studies we reviewed were designed to test aspects of rational models of behavior prediction (i.e., Ajzen's [1991] theory of planned behavior; Fishbein \& Ajzen's [1975] theory of reasoned action; Triandis's [1977] model of interpersonal behavior), the studies used common operations of these variables. The typical measure of attitude was attitude toward the behavior. Participants in the studies rated the extent to which engaging in the target behavior was good or bad (or other characteristics) on adjective rating scales. For the typical measure of subjective norm, participants were asked whether important others think participants should perform the target behavior and then whether the participants were motivated to comply with these others. The tinal norm measure was the product of these rated normative beliefs and motivation to comply. The typical measure of perceived behavioral control assessed how easy or difficult it was for participants to perform the target behavior. The typical measure of intention assessed whether participants intended or planned to perform the target behavior in a given period of time.

Interrater agreement was acceptable $(r=.90)$, and disagreements were resolved through discussion. When more than one correlation was given for any pair of variables within the same study, these correlations were converted to Fisher's $z s$ and were aggregated to yield a mean $z$, which represented the single effect size estimate for that study.

For the analyses, $r$ s were converted to Fisher's $z s$, and each estimate was weighted by the inverse of its variance (i.e., $N-3$ ). In this procedure, estimates with smaller variance, which are more precisely estimated, receive greater weight. A weighted mean $z$ was then calculated across the set of study outcomes (Hedges \& Olkin, 1985).

Significance tests for comparisons between independent effect sizes (i.e., $r$ statistics converted to $z s$ ) used the following formula for contrasts (Rosenthal, 1991; Snedecor \& Cochran, 1967): $z_{\text {difference }}=\left(z_{1}-z_{2}\right) /$ $\left[1 /\left(N_{1}-3\right)+1 /\left(N_{2}-3\right)\right]^{1 / 2}$, in which $N_{1}$ and $N_{2}$ represent the total aggregated number of participants in each of the two groups of studies.

When reporting the results, we converted the weighted mean $z \mathrm{~s}$ back to $r$. The number of studies aggregated in the effect (and not the number of participants, which was used in tests of statistical significance) is noted in parentheses.

\section{Results}

\section{Characteristics of the Typical Study}

The modal study that provided effects assessed past behavior within a given time frame, ranging from 2 weeks up to 12 months. Past behavior was typically measured with a single questionnaire item such as "How often have you performed [the target behavior] in the past [time frame]?' The scale anchors typically specified frequency of performance; for example, for the time frame of 2 weeks, anchors ranged from never to every day. The modal study also predicted both behavioral intentions and behaviors, and it featured one item to assess each of these. Intentions were typically assessed at the same time as past behavior, attitude, and other predictors. That is, for $94 \%$ of the studies, these predictors were assessed at the same time. Future behavior was assessed an average of either 7 or 14 days after these other predictors. The participant sample of the typical study was $17-25$ years old and was $50 \%$ or more females. The modal study was published in a journal and had a completion date in 1991.

\section{Bivariate Correlations Among Past Behavior, Future Behavior, and Other Predictors}

We initially estimated the correlations among measures across the whole sample of studies. As shown in Table 1, past behavior was significantly related to behavioral intentions, $r=.43, p<$ .001 (study outcomes, $n=33$ ) and to future behavior, $r=.39$, $p<.001$ (study outcomes, $n=16$ ). In addition, significant relations emerged between past behavior and the other predictors such that more frequent behavior was associated with more favorable attitudes, less perceived difficulty in controlling the act, and slightly stronger normative pressure to engage in the act.

Consistent with the theory of planned behavior and the theory of reasoned action (Ajzen, 1987; Fishbein \& Ajzen, 1975), the other predictors were significantly related to behavioral intention and to future behavior such that more favorable attitudes, stronger normative pressure, and less perceived difficulty of control were associated with stronger intentions and greater likelihood of future behavior (see Table 1). As would be expected given that attitudes, norms, and control directly affect intentions and that intentions affect behavior, correlations with intentions tended to be larger than with behavior. In general, the findings in our relatively restricted review, which included only those studies that assessed both attitudes and past behavior, are comparable with estimates of prior reviews that were designed to evaluate broader literature (e.g., Kraus, 1995; Sheppard, Hartwick, \& Warshaw, 1988; van den Putte, 1993).

Homogeneity tests were conducted to determine whether it was indeed appropriate to aggregate the studies testing each relationship. The homogeneity statistic, $Q$, has a chi-square distribution with $k-1$ degrees of freedom, in which $k$ represents the number of estimates (Hedges \& Olkin, 1985). A significant result suggests rejection of the hypothesis that the effects are drawn from a common population. As can be seen in Table 1, this statistic was significant for all of the relations estimated except for the perceived control-future behavior effect. It may thus be inappropriate to interpret the estimates for which the test was significant, and it is advisable to conduct moderator analyses to explain the variability across estimates.

\section{Past Behavior Predicts Future Behavior Controlling for Other Predictors}

A number of the reviewed studies used multiple regression designs in which intentions, attitudes, past behavior, subjective norms, perceived behavioral control, and a variety of other variables (e.g., age of participants) predicted behavior. Although these models could not be used to calculate exact effect size estimates, they did provide information on the number of instances in which the past-behavior regression coefficient sig- 
Table 1

Correlations Among Past Behavior, Other Predictors, Behavioral Intention, and Future Behavior and Homogeneity Statistic (Q) for Each Effect

\begin{tabular}{lccccc}
\hline Variable & Future behavior & Past behavior & Intention & Attitude & Subjective norm \\
\hline $\begin{array}{l}\text { Past behavior } \\
r\end{array}$ & $.39 * * *$ & - & & & \\
$n$ & 16 & & & & \\
$Q$ & $283.38^{* * *}$ & & & & \\
Intention & $54^{* * *}$ & $.43^{* * *}$ & - & & \\
$r$ & 19 & 33 & & & \\
$n$ & $307.90^{* * *}$ & $585.71^{* * *}$ & & & \\
$Q$ & & & & \\
Attitude & $.33^{* * *}$ & $.30^{* * *}$ & $.47^{* * *}$ & - & \\
$r$ & 15 & 27 & 37 & & \\
$n$ & $128.56^{* * *}$ & $162.83^{* * *}$ & $402.70^{* * *}$ & & \\
$Q$ & $.23^{* * *}$ & $.09^{* * *}$ & $.31^{* * *}$ & $.31^{* * *}$ & \\
Subjective norm & 16 & 22 & 34 & 25 & \\
$r$ & $82.67^{* * *}$ & $550.66^{* * *}$ & $321.59^{* * *}$ & $274.10^{* * *}$ & \\
$n$ & & & & \\
$Q$ & $-.21^{* * *}$ & $-.36^{* * *}$ & $.49^{* * *}$ & $-.34 * * *$ & $-.07^{* *}$ \\
Perceived control & 4 & 6 & 11 & 9 & 9 \\
$r$ & 4.89 & $22.95^{* * *}$ & $48.63^{* * *}$ & $82.12^{* * *}$ & $129.38^{* * *}$ \\
$n$ & & & & & \\
$Q$ & & & & & \\
\hline
\end{tabular}

Note. Effect sizes are given as bivariate correlations. $n=$ the number of study outcomes aggregated into each effect size estimate. Perceived control is coded so that low numbers represent easily controlled activities, and high numbers represent difficult-to-control activities.

$* * p<.01 . * * * p<.001$.

nificantly predicted future behavior after controlling for these other potential predictors.

Counting analyses identified the number of studies in which past behavior effects were significant in regression models that controlled for other predictors (Hedges \& Olkin, 1985) ${ }^{5}$ Of the 13 studies that reported regression models predicting future behavior from intention and past behavior, 11 revealed that past behavior was a statistically significant predictor of future behavior. The estimated size of the relation between past behavior and intention, based on these frequencies (Bushman, 1994; Hedges \& Olkin, 1985), is $r=.21,95 \%$ confidence interval (CI $=0.14 / 0.29$. Several of these studies included other predictors in addition to intention: In six of six studies, past behavior was significant after controlling for perceived control and intention, which yielded an effect size of $r=.88$. In four of four studies, past behavior was significant after controlling for attitude, subjective norm, and intention, which yielded an effect size of $r=.85 .^{6}$ Although only four studies were available for this critical control analysis (i.e., the examination of the effects of past behavior independent of attitude), these four estimates reflect the data from a total of 1,265 participants. Thus, past behavior emerged as a significant predictor of future behavior, independent of intentions, attitudes, norms, and control. Consequently, past-behavior effects can be interpreted independently of these other variables.

\section{Prediction of Future Behavior From Past Behavior Depends on Opportunity for Performance and Stability of Context}

The opportunity for performing a behavior and the stability of the context in which it was performed proved to be highly correlated, Kendal's $\tau=.76$, such that behaviors with higher opportunity for performance also were more likely to be performed in stable contexts. Given the substantial overlap in coders' ratings of these dimensions, we combined the factors into a single dichotomous index. The first group of studies included behavioral domains that people do not confront very often in daily life and that involve relatively unstable contexts, in which features that maintain the behavior are shifting or are difficult to negotiate. Initiation and performance of acts with these attributes should require some deliberation and control. Consequently, future behavior should be a function of conscious intentions to act, and any effects of past behavior will most likely be indirect, through behavioral intents. The second group of studies included behavioral domains that are encountered more often and that provide a relatively stable context supporting behavior. Such acts are conducive to the development of habitual tendencies to respond. Under these conditions, frequent performance can establish strong habits that yield relatively automatic repetition of past behavior, and past behavior should directly guide future behavior. We did not include in the analysis the

\footnotetext{
${ }^{5}$ For three of the studies predicting behavior, the analyses were reported separately for two different behavioral domains. In these studies, after controlling for intention, past behavior emerged as a significant predictor in one behavioral domain but not in the other. Because'we could not identify a single study outcome that aggregated across the behavioral domains within these studies, they were not included in the counting analyses.

${ }^{6}$ When all studies yield the same outcome in a vote-counting analysis, effect size estimates can be derived by a Bayesian approach to estimating the population correlation (Bushman, 1994; Hedges \& Olkin, 1985). No CIs are available for these estimates.
} 
Table 2

Past Behavior and Other Predictors of Intention and Future Behaviors

\begin{tabular}{|c|c|c|c|c|c|c|}
\hline Variable & $\begin{array}{c}\text { Future } \\
\text { behavior }\end{array}$ & $\begin{array}{c}\begin{array}{c}\text { Past } \\
\text { behavior }\end{array} \\
\end{array}$ & Intention & Attitude & $\begin{array}{c}\text { Subjective } \\
\text { norm }\end{array}$ & $\begin{array}{c}\text { Perceived } \\
\text { control }\end{array}$ \\
\hline \multicolumn{7}{|c|}{ Future behavior } \\
\hline$r$ & - & $.59 * *$ & $.52 * *$ & $.30 * *$ & $.10^{* *}$ & $-.31 * *$ \\
\hline$n$ & & 5 & 8 & 5 & 5 & 1 \\
\hline \multicolumn{7}{|l|}{ Past behavior } \\
\hline$r$ & $.27 * *$ & - & $.60^{* *}$ & $.35^{* *}$ & $-.32 * *$ & $-.26^{* *}$ \\
\hline$n$ & 5 & & 10 & 11 & 4 & 2 \\
\hline \multicolumn{7}{|l|}{ Intention } \\
\hline$r$ & $.55^{* *}$ & $.32^{* *}$ & 一 & $.44 * *$ & $.16 * *$ & $-.44 * *$ \\
\hline$n$ & 5 & 10 & & 13 & 11 & 3 \\
\hline \multicolumn{7}{|l|}{ Attitude } \\
\hline$r$ & $.30^{* *}$ & $.23^{* *}$ & $.51 * *$ & - & .06 & $-.35^{* *}$ \\
\hline$n$ & 5 & 5 & 10 & & 4 & 2 \\
\hline \multicolumn{7}{|c|}{ Subjective norm } \\
\hline$r$ & $.25^{* *}$ & $.22 * *$ & $.39 * *$ & $.39 * *$ & - & $.21 * *$ \\
\hline$n$ & 5 & 5 & 10 & 5 & & 2 \\
\hline \multicolumn{7}{|c|}{ Perceived control } \\
\hline$r$ & & & $-.38 * *$ & $-.18 * *$ & $-.19 * *$ & - \\
\hline$n$ & & & 3 & 3 & 3 & \\
\hline
\end{tabular}

Note. Effect sizes represent bivariate correlations $(r)$. Estimates above the diagonal represent behavior performed daily or weekly in stable contexts, and estimates below the diagonal represent behaviors performed annually or biannually in unstable contexts. $n=$ the number of study outcomes aggregated into each effect size estimate. Perceived control is coded so that low numbers represent easily controlled activities and high numbers represent difficult-to-control activities.

$* * p<.01$.

few study outcomes in which opportunity for performance and context had disparate codes (i.e., high opportunity in low-stability contexts or low opportunity in high-stability contexts)?

Consistent with these expectations, frequency of past behavior was a weaker predictor of future behavior in domains that are encountered only annually or biannually and that present unstable contexts, $r=.27, p<.001$, than in domains encountered on a daily or weekly basis and that present stable contexts, $r=.59, p<.001 ; z_{\text {difference }}=8.98, p<.001$ ( see Table 2). Also as anticipated, intentions and attitudes had uniform effects in the prediction of future behavior; their impact was not modified by performance opportunity and context stability. We had anticipated that subjective norms would function like attitudes and be relatively insensitive to the study groupings. However, norms proved to be a stronger predictor for behaviors performed annually or biannually in changing contexts than for behaviors performed daily or weekly in stable settings, $z_{\text {difference }}=3.61$, $p<.001$. Too little data were available concerning perceived behavioral control to evaluate the effects of this predictor.

A number of other effect size estimates varied with performance opportunity and context stability. In general, conscious, rational predictors of intentions demonstrated stronger relations for behaviors performed annually or biannually in changing contexts than behaviors performed daily or weekly in stable contexts. Thus, attitudes had a stronger impact on intentions in domains that encouraged deliberatively guided behavior, $r=$ $.51, p<.001$, than in domains that supported habits, $r=.44$, $p<.001 ; z_{\text {difference }}=3.23, p<.001$. Similarly, subjective norms had stronger impact in domains that encouraged deliberatively guided behavior, $r=.39, p<.001$, than in domains that supported habits, $r=.16, p<.001 ; z_{\text {difference }}=8.30, p<.001$.
Although we had not predicted this pattern, it suggests that, when people are consciously deliberating about acts, they form intentions in a careful, thoughtful manner that considers evaluations of the outcomes of the behavior (i.e., attitudes) and others' preferences (i.e., norms ). In domains conducive to habit formation, people may base intentions on less ambiguous, perhaps more easily determined cues such as past act frequency. Indeed, past behavior was a stronger predictor of intentions in domains that supported habit formation, $r=.60, p<.001$, than in domains that encouraged deliberative thought, $r=.32, p<$ $.001 ; z_{\text {difference }}=11.77, p<.001$.

\section{Does Past Behavior Directly Predict Intention?}

A secondary focus of the present investigation was to examine whether past behavior directly predicts intention or whether it contributes to attitudes or to perceived control and only indirectly predicts intents. We evaluated whether past behavior predicts intention independent of these other factors. Counting analyses identified the number of studies in which past behavior emerged as a significant predictor of intentions in regression models that controlled for other predictors. In 19 of 22 studies, past behavior was a significant predictor in the regression models after controlling for both attitudes and subjective norm. The estimated size of the relation between past behavior and intention, based on these frequencies (Bushman, 1994; Hedges \& Olkin, 1985), is $r=.25,95 \%, \mathrm{CI}=0.18 / 0.30$. In 8 of the 9

\footnotetext{
${ }^{7}$ The number of study outcomes that were excluded varied across analyses, with the modal number being 4 .
} 
studies that also controlled for perceived control, past behavior emerged as a significant predictor, yielding an effect size estimate of $r=.28,95 \% \mathrm{CI}=0.16 / 0.38$. It appears, then, that frequency of past behavior directly predicts intentions. It may still be the case that past behavior contributes to attitudes, norms, and control, but past behavior has direct effects on intentions independent of these other predictors.

\section{Modeling Joint Effects of Past Behavior and Intention on Future Behavior}

As we had anticipated, both intentions and past behavior predicted future behavior. The direct effects of past behavior were most pronounced in domains supportive of routinized response repetition, although the effects of intentions on future behavior proved constant across domains. We claim that, in domains supportive of habits, past behavior has direct effects on future responses, unmediated by thoughts and perceptions, which are represented by intentions (and the attitudes, norms, and perceived control on which intentions are based). However, when behavior requires deliberative thought, past behavior contributes to intentions and affects future performance primarily through the mediation of intentions. These ideas cannot be evaluated from bivariate correlations among the variables; to do so requires simultaneous assessment of the effects of past behavior and intentions on future behavior. Thus, we used the bivariate correlations to estimate path models from the synthesized data.

The path analyses were conducted with generalized least squares (GLS) regression ( see Becker, 1992; Becker \& Schram, 1994). The first step in this analysis involved estimating a pooled correlation matrix of the relations among past behavior, intention, and future behavior. First, a matrix was constructed to represent the zero-order relations among the variables for each of the 15 studies that provided sufficient data. These matrixes were used to calculate variance-covariance matrixes for each study. Using GLS formulas (provided by Becker, 1992), and the matrix utility SAS PROC IML (1989), we aggregated the variance-covariance matrixes and estimated a single pooled correlation matrix and standard errors. Homogeneity tests were conducted to determine whether the single correlation matrix could adequately describe all of the sample results. The homogeneity statistic, $Q_{\mathrm{E}}$, has a chi-square distribution with $(k-1) p$ degrees of freedom, in which $k$ represents the number of independent studies being combined and $p$ represents the number of correlations drawn from each study (see Becker \& Schram, 1994). This test of fit indicated significance, $Q_{\mathrm{E}}(39, N=14)$ $=971.82, p<.001$, suggesting that all study results do not share a common population value and that additional predictors are necessary to adequately account for the effects.

The studies were then grouped into two sets. One reflected domains conducive to habits, domains in which people have the opportunity to perform behaviors daily or weekly and the context is stable ( study outcomes, $n=8$ ). These included exercise, eating at fast food restaurants, class attendance, seat belt use, drinking milk, and church attendance. The other set included domains that require deliberation and control, in which behaviors can be performed only annually or biannually and the supporting context is unstable (study outcomes, $n=6$ ). These included blood donation, voting, obtaining a flu shot, and ob- taining a mammogram. Separate pooled correlation matrixes and their standard errors were calculated for each group (see Table 3). Homogeneity tests conducted separately on the two groups proved to be significant, $Q_{E}(21, N=8)=145.72$ for high-opportunity, high-stability domains and $Q_{\mathrm{E}}(15, N=6)=$ 518.13 for low-opportunity, low-stability groups, $p \mathrm{~s}<.001$. This variability is not surprising given our rather global distinction between these two types of domains. Some of the behavioral domains classified as providing high opportunity for performance and stable contexts likely supported greater automaticity in behavioral repetition than did others in this category. Similarly, not all of the domains classified as having low-opportunity, unstable contexts impeded habits and required thoughtful deliberation to the same extent.

In the next step in the analysis, we estimated a standardized regression equation predicting future behavior from past behavior and intentions with the data from the two sets of pooled matrixes (see Table 4). As can be seen in Figure 1 (Panel A), the path model for acts typically performed annually or biannually in unstable contexts revealed that both intentions and past behavior were significant predictors of future behavior ( $p \mathrm{~s}$ $<.001$ ). As anticipated, however, past behavior effects were small, and intentions were a significantly stronger predictor, $z$ $=17.15, p<.001$ ( see Becker \& Schram, 1994, p. 371, for the test of the difference between regression coefficients ). Thus, in these behavioral domains, consciously formed intentions predicted future behavior directly. Past behavior had a relatively minimal direct impact on future responses. The path model for behavior performed on a daily or weekly basis in constant contexts again revealed that both intentions and past behavior were significant predictors $(p s<.001)$. However, as predicted, past behavior had a strong direct impact. Its effect was significantly larger than that of intention, $z=2.82, p<.001$ (see Figure 1, Panel B). Thus, in domains conducive to habit formation, people tended to directly repeat past acts, presumably because frequently performed behaviors were automatically cued by the stable environment. In these domains, conscious intentions had a less marked impact on future responses.

We also considered how the impact of past behavior on future behavior varied across domains. Comparison between the pastbehavior regression coefficients in the two study groupings ( $\mathrm{Co}-$

Table 3

Pooled Correlation and Variance-Covariance Matrixes

\begin{tabular}{llll}
\hline Variable & Past behavior & Intention & Future behavior \\
\hline Behaviors performed annually or biannually in unstable contexts \\
Past behavior & .00028 & .00016 & .00005 \\
Intention & .40 & .00031 & .00005 \\
Future behavior & .37 & .67 & .00014 \\
\hline
\end{tabular}

Behaviors performed daily or weekly in stable contexts

\begin{tabular}{llll} 
Past behavior & .00025 & .00009 & .00013 \\
Intention & .70 & .00032 & .00017 \\
Future behavior & .64 & .59 & .00039 \\
\hline
\end{tabular}

Note. Coefficients above the diagonal for each set of data represent covariances, coefficients on the diagonal represent variances, and coefficients below the diagonal represent zero-order correlations. 
Table 4

Generalized Least Squares Regression Results Predicting Future Behavior From Past Behavior and Intentions

\begin{tabular}{llllll}
\hline Predictor & $B$ & $S E$ & $t$ & CI (lower/upper) \\
\hline
\end{tabular}

Behaviors performed annually or biannually in unstable contexts ${ }^{\mathrm{a}}$

\begin{tabular}{llrrr} 
Past behavior & 0.12 & .018 & $6.85^{* * *}$ & $0.09 / 0.15$ \\
Intention & 0.62 & .018 & $34.07^{* * *}$ & $0.58 / 0.66$ \\
\hline
\end{tabular}

Behaviors performed daily or weekly in stable contexts ${ }^{\mathrm{b}}$

\begin{tabular}{lllrl} 
Past behavior & 0.45 & .033 & $15.15^{* * *}$ & $0.39 / 0.51$ \\
Intention & 0.27 & .034 & $7.94^{* * *}$ & $0.20 / 0.34$ \\
\hline
\end{tabular}

Note. Effect size estimates are reported as $r \mathrm{~s} . \mathrm{CI}=95 \%$ confidence interval.

${ }^{a} \mathrm{~N}$ study outcomes $=6 .{ }^{\mathrm{b}} \mathrm{N}$ study outcomes $=8$.

$* * * p<.001$.

hen $\&$ Cohen, 1983) revealed stronger effects for past behavior in domains conducive to habit formation than in domains not conducive to habits, $z=-8.85, p<.001$. A similar analysis conducted on the intention regression coefficients revealed that intention was a stronger predictor in domains not conducive to habits, $z=9.07, p<.001$.

\section{Methodological Artifacts}

A number of measurement factors could inflate or attenuate the behavior-behavior relationship; such factors include the time interval between measures, specificity of the behavioral criterion and the variance of the measure, and similarity between the two measures of behavior (Sutton, 1994). It could be argued that these account for the path analytic results. For example, in domains not conducive to habits, the link between past and future behaviors might be suppressed due to such measurement artifacts, and the apparent effects of intentions would then be enhanced because of the lesser predictive ability of past behavior.

First, we considered whether the time span between measures could explain the path analytic findings. For all of the studies included in the path analysis, the intention and the past behavior measures were obtained at the same lime and in the same reporting context (i.e., with the exception of a single study in the domains conducive to habit formation, this study assessed past behavior 2 weeks prior to assessing intention). Thus, the results were not due to differential timing of intention and past-behavior measures. Furthermore, for domains supportive of habits, the mean delay between assessments of intention and future behavior was 49.67 days, and the mean delay between assessments of past and future behaviors was 55.83 days. For domains not conducive to habits, the mean delay for both intentions and past behavior was 79.75 days. Given that greater delay should be associated with less predictive power of intentions and of past behavior, delay could not have accounted for the differential impact of intention and past behavior within each study grouping.

Second, our findings do not appear to be due to problems with the reliability or the variability of the past-behavior measure in domains not conducive to habits. Low reliability or minimal variability in the past-behavior measure would inflate the apparent predictive power of other factors and could explain why intention had a relatively strong effect in this study grouping. However, problems with reliability or variability in a measure should attenuate all relations between that variable and other factors. As can be seen in Table 5, which reports the bivariate correlations for studies included in the path analysis, past behavior was actually more strongly related to subjective norms in domains conducive to habit formation than in domains not supportive of habits. Although this particular effect is not theoretically meaningful, it does suggest that reliability and variability of the behavior measures did not vary importantly across our study groupings.

Finally, the differential effects of intention in the two domains were not due to the way intention was measured. In both domains, approximately two thirds of the studies assessed behavioral intentions, and only a third assessed behavioral expectations.

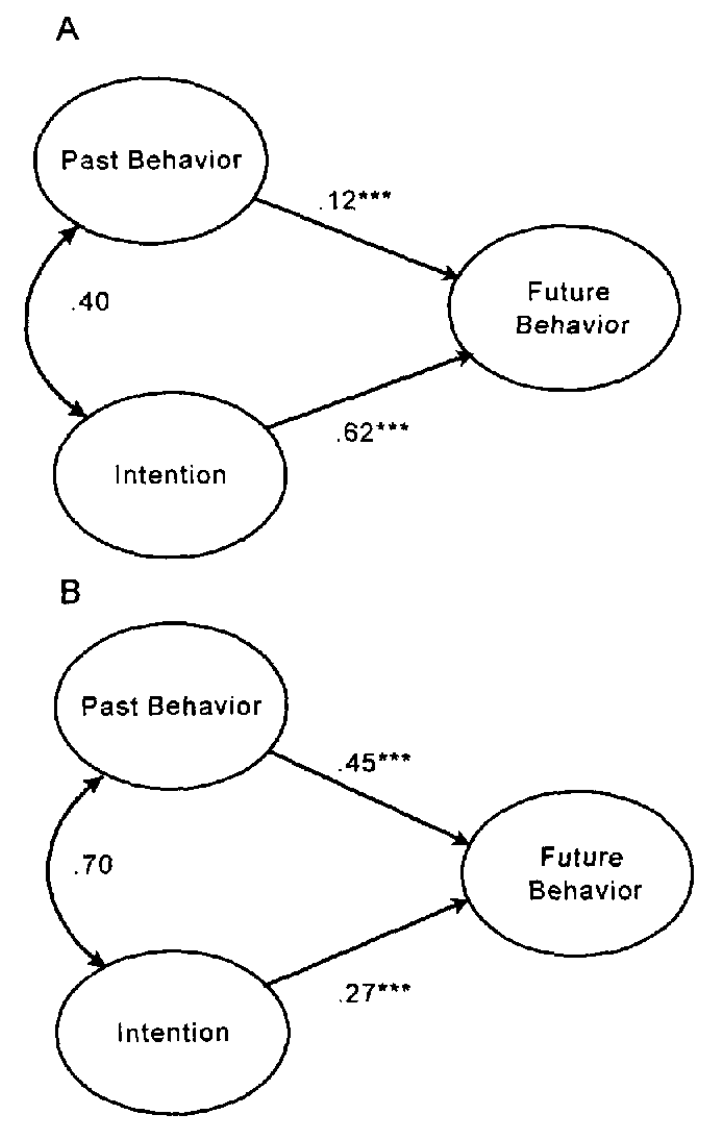

Figure 1 . The models display the results of generalized least squares regressions predicting future behavior frequency from past behavior and behavioral intentions. Panel A represents findings from those studies examining behaviors that are performed annually or biannually and that occur in unstable contexts. Panel B represents findings from those studies examining behaviors that are performed daily or weekly in stable contexts. The numbers appended to the single-headed arrows are standardized regression coefficients (betas), and the numbers appended to the double-headed arrows are bivariate correlation coefficients $(r) . * * * p$ $<.001$. 
Table 5

Correlations Among Predictors for Studies Included in Path Analysis

\begin{tabular}{|c|c|c|c|c|c|}
\hline Variable & Future behavior & Past behavior & Intention & Attitude & Subjective norm \\
\hline \multicolumn{6}{|c|}{ Future behavior } \\
\hline$r$ & - & .64 & .59 & .31 & .11 \\
\hline$n$ & & 9 & 9 & 5 & 5 \\
\hline \multicolumn{6}{|l|}{ Past behavior } \\
\hline$r$ & .37 & - & .70 & .39 & .07 \\
\hline$n$ & 6 & & 9 & 5 & 4 \\
\hline \multicolumn{6}{|l|}{ Intention } \\
\hline$r$ & .67 & .40 & - & .46 & .18 \\
\hline$n$ & 6 & 6 & & 7 & 6 \\
\hline \multicolumn{6}{|l|}{ Attitude } \\
\hline$r$ & .30 & .24 & .51 & - & .25 \\
\hline$n$ & 5 & 4 & 6 & & 5 \\
\hline \multicolumn{6}{|c|}{ Subjective norm } \\
\hline$r$ & .25 & .23 & .39 & .41 & - \\
\hline$n$ & 5 & 4 & 6 & 4 & \\
\hline
\end{tabular}

Note. $n=$ number of studies aggregated in the effect. Correlations above the diagonal are for highopportunity, high-stability contexts, and correlations below the diagonal are for low-opportunity, low-stability contexts. All correlations with attitudes and subjective norms are simple aggregated bivariate correlations. Correlations in boldface are bivariate correlations obtained by pooling the variance-covariance matrixes of the individual studies; this aggregation method was used for the data entered into the path analyses.

\section{Methodological Moderators}

We expected past behavior to be more closely related to measures of intention that were phrased in terms of expectancies for future performance than to measures that specified conscious plans to complete the act. Indeed, past behavior proved to be a better predictor of behavioral expectations, $r=.45$ (study outcomes, $n=13$ ), than of behavioral intentions, $r=.40$ (study outcomes, $n=19$ ); $z_{\text {difference }}=3.02, p<.01$. Thus, past behavior was more strongly related to intentions that reflected the simple likelihood of the act in the future than to intentions that reflected decisions to act.

We also examined whether the relation between past behavior and intention depended on the order in which the variables were measured in the reviewed studies. If intentions and past behavior are related because intentions are in part likelihood judgments based on past incidence, then the relation between these variables should be stronger when past behavior is assessed prior to intentions - thus, past action (or inaction) would be highly salient-than when past behavior is assessed following intentions. Indeed, past behavior proved to be a better predictor of intention when it was assessed first, $r=.64$ (study outcomes, $n=5$ ), than when intention was assessed first, $r=.41$ ( study outcomes, $n=28$ ); $z_{\text {difference }}=8.41, p<.001$.

The number of items used in the questionnaires also emerged as a moderator in our review. Past-behavior measures composed of more than one item were marginally more successful at predicting future behavior, $r=.45$ (study outcomes, $n=6$ ), than measures composed of a single item, $r=.38$ (study outcomes, $n=10), p<.07$, for the comparison between different numbers of items. Similarly, greater success in predicting intentions was observed when the past-behavior measure was composed of more than one item, $r=.63$ (study outcomes, $n=10$ ), than when composed of a single item, $r=.39$ (study outcomes, $n$ $=22$ ), $p<.001$, for the comparison. Thus, studies that obtained more reliable measures generated stronger effects.

\section{Discussion}

Past behavior emerged as an important predictor of future behavior in the studies in our review. Overall, when the findings were aggregated across the full set of studies, the magnitude of the effect of past behavior on future behavior, $r=.39, p<$ .001 , was about comparable with that of other predictors. That is, the impact of frequency of past behavior was slightly weaker than that of intentions, $r=.54$, approximately the same size as the effect of attitudes, $r=.33$, and slightly stronger than the effects of behavioral control (i.e., difficulty of performance), $r$ $=-.21$, and of subjective norms, $r=.23$.

The findings also provide good support for our theoretical analysis of the multiple mechanisms through which past behavior can affect future responses. Past behavior directly contributes to future performance in contexts that support the development of habits. Behaviors that are well practiced and performed in stable contexts are likely to be repeated because they can be performed quickly, relatively effortlessly, in parallel with other activities, and with minimal or sporadic attention (Bargh, 1989; Logan, 1989). Conscious deliberation and decision making are not required for performance of such acts. Although habitual behaviors may be intentional and goal directed, the controlling intentions are not typically accessible to consciousness, because with repeated performance (a) intentions themselves tend to become automatic; (b) intentions tend to be specified in an efficient, stable, and general form that emphasizes the goals met by the action rather than action details; and (c) intentions, much like the actions they direct, tend to be combined into broader and more efficient units that refer to sets of behaviors that occur together rather than to individual actions.

In our review, behavioral domains conducive to habit formation were defined as those in which behaviors could be performed on a daily or weekly basis in a stable, predictable supporting context. These included alcohol and coffee consumption, most types of exercise, seat belt use, and class and church 
attendance. A path model that estimated future performance of these behaviors from past-behavior frequency and behavioral intentions revealed a strong direct effect of past behavior on future responses. Thus, for these types of behaviors, it appears that frequent past performance reflects habits that automatically guide future responses. Intentions had a much smaller effect in these domains but remained a significant predictor of future behavior.

We further anticipated that past behavior would have a minimal direct effect on future responses when people consciously deliberate about actions. Conscious deliberation and decision making likely are required to initiate and execute novel behaviors and behaviors that are performed in difficult or changing contexts. In these domains, past-behavior frequency is one factor that might inform participants' judgments of intention. In the present review, we anticipated that conscious deliberation would be required in domains that (a) provided minimal opportunity for performance, in which behaviors occurred only annually or biannually and (b) presented unstable, shifting contexts that did not provide a constant set of cues supporting behavior performance. In the present review, behaviors classified as low in opportunity for performance and low in stability of supporting context included voting, preventative health behaviors (e.g., getting a flu shot or a mammogram), blood donation, and exercise after childbirth or after experiencing a heart attack. In the path model estimating future performance of these behaviors based on past behavior frequency and behavioral intentions, conscious intentions emerged as a strong predictor. Past-act frequency had a small although statistically significant effect on future responses. It seems that when behavior is a function of conscious decision making and deliberation, intentions directly predict behavior performance, and the effects of past behavior are likely to be mediated through conscious intents. Indeed, the correlation between intention and past behavior in this context $(r=.40)$ implies that intentions were drawn from incidence of past behavior, with people reasoning that they performed (or did not perform) a behavior in the past and would continue to do so (or not) in the future.

Deliberations about future behavior likely include more than just past behavior. According to Ajzen's (1987) theory of planned behavior, intentions reflect attitudes toward the act, subjective norms, and perceived behavioral control. The bivariate correlation analyses were consistent with the idea that behavioral intentions reflect these other factors, especially in behavioral domains that people encounter rarely or that entail changing contexts. That is, attitudes and subjective norms had especially strong effects on intentions in such contexts. This coherence among intentions, attitudes, and norms is consistent with the idea that people are deliberately reasoning about their behavior in such domains. Reasoning how to act in these domains is likely to render evaluative beliefs, normative beliefs, and behavioral intents relatively consistent.

It is interesting that, contrary to the pattern that emerged with attitudes and subjective norms as predictors of intention, past behavior was more closely related to intention in domains in which automatic, habitual tendencies were likely to develop rather than in domains requiring conscious decision making. Although we did not specifically anticipate this result, it is consistent with the idea that, when people are asked to give conscious intentions for habitual behaviors, they do not generate especially thoughtful responses based on their evaluations and subjective norms. Instead, people may rely on salient, tangible instances of past behavior, which should be especially accessible in domains with high opportunity for performance.

In general, intention and past behavior appeared to alternate as predictors of future acts. In domains that facilitated development and execution of habits, past behavior was a strong predictor and intention relatively weak. In domains that did not facilitate habits, past behavior was a relatively weak direct predictor and intention was quite strong. One interpretation of this pattern is that intention effects emerge primarily in the absence of habit. We suspect that the relation between intention and habit is actually more complex than suggested by such a broad generalization, which does not allow for such phenomena as New Year's resolutions, in which strongly held intentions can, at least temporarily, override the effects of habit.

\section{Interpreting Past Behavior Effects}

Interpreting the effects of past behavior on future acts has been difficult because past behavior is itself a product of a variety of psychological states. In the meta-analytic synthesis, we were able to eliminate several of the most obvious confounds. The counting analyses revealed that past behavior independently predicted future behavior in studies that had conducted analyses controlling for the effects of intentions, attitudes toward the act, subjective norms, and perceived behavioral control. Thus, the effects of past behavior cannot be attributed to these potential confounds.

However, the correlational nature of these data leaves open the possibility that some additional unmeasured factor is confounded with past behavior frequency and is actually responsible for the obtained pattern. Two explanations in particular merit comment. Given that direct experience with an attitude object yields attitudes (and perhaps intentions) that are held more strongly and with greater certainty (Fazio, Chen, McDonel, \& Sherman, 1982; Petty \& Krosnick, 1995), it could be that frequent past behavior increases the strength of attitudes. One index of strength is the ease with which attitudes can be accessed from memory (Fazio, 1990), and it may be that past behavior serves as a proxy for attitude accessibility.

In addition, past behavior could be confounded with beliefs about the self. It could be that people who report that they have engaged in a behavior frequently in the past have a corresponding self-concept, and it is this self-view that guides future performance. Given the way that past behavior was measured in the reviewed studies, however, we do not find the self-concept account especially compelling. Participants in most of the studies were asked to give subjective estimates of the frequency with which they performed the target behavior. Thus, respondents who donated blood twice a year would rate on the scale that they were "frequent" blood donors much like people who drank coffee daily would rate that they were "frequent" coffee drinkers. It seems likely then that people who reported frequent performance in these two domains considered themselves regular blood donors and coffee drinkers, although past-behavior effects emerged primarily with coffee-drinking type behaviors (i.e., when opportunity and stability were high). 
Unfortunately, the information necessary to evaluate empirically these alternate interpretations of past behavior effects was not provided in the reviewed studies. However, primary research data that address these issues are available. As part of her dissertation research, Ouellette (1996) investigated the role of behavior frequency, context stability, attitude accessibility, and selfconcept in predicting future behavior.

\section{Ouellette's (1996) Investigation of Past Behavior Effects on Future Behavior}

In one part of this research, 141 Texas A\&M University undergraduate students completed a two-part experiment concerning their TV watching and their recycling behavior. In the first session, they completed a series of questionnaire measures, evaluating (a) frequency of past behavior (assessed from estimates of the number of times, for each of the previous 6 months, that participants had engaged in the behavior), (b) subjective norm (rated on a 9-point scale evaluating whether "people whose opinions are important to me think that it is good if I watch TV/recycle" ranging from 1 [strongly disagree] to 9 [strongly agree]), (c) perceived behavioral control (rated on a 9-point scale ranging from 1 [very easy] to 9 [very difficult]), (d) intention to perform the act (rated on a 9-point scale ranging from 1 [very unlikely] to 9 [very likely]), (e) self-concept measures of whether participants thought of themselves as regular TV watchers or regular recyclers (on a 10-point scale ranging from 1 [absolutely false] to 9 [absolutely true]), (f) an assessment of attitudes that yielded favorability (across six 9-point semantic differential scales for each behavior), and ( $\mathrm{g}$ ) a computerized assessment of attitude accessibility (i.e., response latency to rate the attitude on the scales; see Fazio, 1990).

TV watching and recycling would have been classified as high-opportunity behaviors in the meta-analytic synthesis, because people can perform these behaviors on a daily or weekly basis. However, even with frequent performance in a domain, behaviors are likely to be repeated automatically only when they occur in stable, predictable contexts. To assess stability of the supporting context, participants completed an open response measure in which they listed what they would always do (if anything) before watching TV and before recycling. The number of factors listed were counted and, on the basis of this measure, two groups of participants were selected. One group was composed of those who did not list any consistent antecedents to performing the behavior ( $n s=39$ and 90 for watching TV and recycling, respectively) and those who listed at least two stable antecedents ( $n \mathrm{~s}=33$ and 9 , for TV and recycling, respectively). It is interesting to note that frequency of past behavior was correlated with the number of antecedents listed only for one of the behaviors $(r s=-.03, n s$, and $.35, p<.01$, for watching TV and recycling, respectively).

Three weeks later, participants were recontacted for an (ostensibly unrelated) telephone survey in which they reported the frequency with which they had watched TV and recycled during the period since the first assessment. The correlations among measures for each behavior are given in Table 6 .

We anticipated that the results of this study would parallel those obtained in the meta-analytic synthesis. That is, in regression models predicting future behavior, frequency of past behavior should interact with context stability. In stable contexts, past behavior should be a strong, direct predictor, whereas in unstable contexts past-behavior effects should be mediated by intention, and intention should be the primary predictor of future acts. Furthermore, we expected these patterns to obtain even when other potential predictors of behavior were entered into the regression models (i.e., self-concept and attitude accessibility).

We first constructed regression models to replicate the path analysis in the meta-analytic synthesis. Frequency of future behavior was predicted from frequency of past behavior, intention, context, the interaction between past behavior and context, and the interaction between intention and context. The results were essentially identical across watching TV and recycling and well replicated the meta-analytic findings: In the overall models, the main effects for intention were significant (unstandardized $b$ s $=2.14$ and 0.80$), t(68)=3.09$ and $t(97)=4.47, p s<.01$, for TV and recycling, respectively, and the interactions between past behavior and context approached significance $(b s=0.31$

Table 6

Bivariate Correlations in Ouellette (1996)

\begin{tabular}{|c|c|c|c|c|c|c|c|c|}
\hline Variable & Future & Past & Intent & Attitude & $\begin{array}{l}\text { Subjective } \\
\text { norm }\end{array}$ & $\begin{array}{l}\text { Perceived } \\
\text { control }\end{array}$ & $\begin{array}{l}\text { Attitude } \\
\text { accessibility }\end{array}$ & Self \\
\hline Future & - & $.55 *$ & $.58^{*}$ & $.40^{*}$ & .20 & $-.30^{*}$ & .04 & $.63^{*}$ \\
\hline Past & $.48^{*}$ & - & $.52 *$ & $.35^{*}$ & .19 & $-.40^{*}$ & -.02 & $-.53 *$ \\
\hline Intent & $.43 *$ & $.41 *$ & - & $.62^{*}$ & $.32 *$ & $-.65 *$ & -.07 & $.68^{*}$ \\
\hline Attitude & .12 & .17 & $.36^{*}$ & - & $.55^{*}$ & $-.52^{*}$ & -.05 & $.50 *$ \\
\hline Subjective norm & $.35^{*}$ & $.24 *$ & $.48 *$ & $.40^{*}$ & - & -.20 & -.10 & $.24^{*}$ \\
\hline Perceived control & $-.43 *$ & $-.43^{*}$ & $-.74^{*}$ & $-.31 *$ & $-.39 *$ & - & .09 & $-.44 *$ \\
\hline Attitude accessibility & -.13 & -.12 & $-.34 *$ & $-.33 *$ & -.16 & $-.30 *$ & - & -.11 \\
\hline Self & $.41 *$ & $.48^{*}$ & $.69 *$ & $.22^{*}$ & $.41 *$ & $-.79 *$ & -.17 & - \\
\hline
\end{tabular}

Note. Future $=$ future behavior; Past $=$ past behavior; Self $=$ self-concept. Higher numbers represent more frequent future behavior, more frequent past behavior, stronger intentions to perform the behavior, more favorable attitudes, more favorable perceived norms, greater perceived difficulty performing the behavior, lesser accessibility of attitudes, and a self-concept as a performer of the behavior. Effects above the diagonal represent watching television $(n=71$ ), and effects below the diagonal represent recycling ( $n=99$ for all estimates except those involving attitudes, for which $n=98$ ).

$* p<.05$. 
Table 7

Bivariate Correlations for Prediction of Watching Television in Ouellette (1996)

\begin{tabular}{|c|c|c|c|c|c|c|c|c|}
\hline Variable & Future & Past & Intent & Attitude & $\begin{array}{c}\text { Subjective } \\
\text { norm }\end{array}$ & $\begin{array}{c}\text { Perceived } \\
\text { control }\end{array}$ & $\begin{array}{c}\text { Attitude } \\
\text { accessibility }\end{array}$ & Self \\
\hline Future & - & $.59 * *$ & $.46^{* *}$ & .33 & .20 & .07 & -.01 & $.38 *$ \\
\hline Past & $.56^{* *}$ & - & $.36^{*}$ & $.37 *$ & .15 & -.21 & -.06 & $.44^{*}$ \\
\hline Intent & $.63^{* *}$ & $.62 * *$ & - & $.70^{* *}$ & $.45 * *$ & -.24 & .01 & $.52 * *$ \\
\hline Attitude & .40 & .38 & $.55^{* *}$ & - & $.78 * *$ & $-.51 * *$ & -.02 & $.42^{*}$ \\
\hline Subjective norm & .18 & .23 & .23 & $.36 *$ & - & $-.36^{*}$ & -.11 & .21 \\
\hline Perceived control & $-.43^{* *}$ & $-.50 * *$ & $-.78 * *$ & $-.51 * *$ & -.11 & - & -.10 & -.11 \\
\hline Attitude accessibility & .02 & .01 & -.18 & -.17 & -.13 & .25 & - & -.27 \\
\hline Self & $.77^{* *}$ & $.64 * *$ & $.74 * *$ & $.49 * *$ & .24 & $-.55^{* *}$ & -.09 & - \\
\hline
\end{tabular}

Note. Future $=$ future behavior; Past $=$ past behavior; Self $=$ self-concept. Variables were scored so that higher numbers represent more frequent future behavior, more frequent past behavior, stronger intentions to perform the behavior, more favorable attitudes, more favorable perceived norms, greater perceived difficulty performing the behavior, lesser accessibility of attitudes, and a self-concept as a performer of the behavior. Coefficients above the diagonal represent behavior performed in stable contexts $(n=33$ ), and coefficients below the diagonal represent behavior performed in unstable contexts $(n=38)$

$* p<.05 . \quad * * p<.01$.

and 0.63$), t(68)=1.83$ and $t(97)=3.34, p s<.07$, for TV and recycling. More important, when the simple regression slopes within context were calculated for each behavior (see Aiken \& West, 1991), only frequency of past behavior was a predictor in stable contexts ( $b s=0.39$ and 0.52$), t(31)=2.25$ and $t(6)=7.06, p \mathrm{~s}<.05$ for TV and recycling, respectively, and only intention was a strong predictor in unstable contexts $(b \mathrm{~s}=2.14$ and 0.80$), t(37)=3.85$ and $t(91)=4.37, p \mathrm{~s}<$ .001 , for TV and recycling, respectively. As in the meta-analytic synthesis, for behaviors that are performed in stable contexts, frequent past behavior reflects habitual tendencies and directly determines future behavior. Conscious intentions had little effect, $t(31)=1.49$ and $t(6)=0.07, n s$, for TV and recycling, respectively. For behaviors that are performed in unstable contexts for which there are no established antecedents, frequent past performance does not reflect habits; the effects of past behavior are then mediated by conscious intentions, and only intention is a direct predictor of future behavior. Past behavior was not significant, $t(37)=1.26$ and $t(91)=-0.82, n s$.

Regression models also were calculated to examine the effects of intention and past behavior in conjunction with attitude accessibility and self-concept. We anticipated that the effects of accessibility and self-concept would be similar to those of intention in these models. That is, automatic repetition of frequently performed behavior in stable contexts should emerge after controlling for the effects of accessibility and self-concept. Furthermore, because accessibility and self-concept reflect many factors in addition to frequency of past behavior, we anticipated that these factors would independently predict future behavior. Bivariate correlations between the variables in the model, which were calculated separately for high- and low-stability contexts, are presented in Tables 7 and 8 . The regression models are presented in Tables 9 and 10. Given the large number of predictors and the relatively small sample size, we were unable to include in the models any interactions but the two-way interactions between past behavior and other factors (see design in Tables 9 and 10). Essentially, the findings again replicated the meta-analytic results and suggested that past behavior had unique effects on future behavior. That is, the Past Behavior $x$
Context interactions were significant in the overall models in both behavioral domains. Furthermore, in the simple effects decomposition within context, past behavior was a significant predictor within stable but not unstable contexts. Also as predicted, conscious judgments, self-concept and intention in particular, were significant predictors in unstable but not stable contexts. In unstable contexts, future TV watching behavior was a function of conscious inferences about the self, and frequency of recycling was a function of conscious intentions, ${ }^{8}$ Attitude accessibility, however, had no effect in any context, and including this term did not weaken the predictive power of past behavior.

These findings provide strong support for our theorizing about the conditions under which past behavior directly affects future performance and when it has an indirect effect, mediated through intention. The results also demonstrate that past-behavior effects are not confounded with attitude accessibility or with the self-concept and, in support of the meta-analytic findings, that past-behavior effects are not confounded with intentions, attitudes, subjective norms, or perceived control.

\footnotetext{
${ }^{8}$ We also computed these analyses substituting the components of behavioral intention (i.e., attitude, subjective norm, and perceived behavioral control) for the intention predictor, and the results were largely consistent with those reported in the text. The overall models predicted future behavior from attitude, subjective norm, past behavior, context, perceived control, attitude accessibility, self-concept, and the two-way interactions among context and past behavior, attitude, subjective norm, accessibility, perceived control, and self-concept. For recycling, significant relations included subjective norm, perceived control, and Past Behavior $\times$ Context $(p s<.05$ ). For watching TV, significant relations included self-concept, Past Behavior $\times$ Context, and Self-Concept $\times$ Context $(p \mathrm{~s}<.05)$. As with the models reported in the text, we then computed simple effects analyses examining the predictors within levels of context. For recycling, subjective norm and perceived control predicted future behavior $(p s<.05)$ in unstable contexts, and only past behavior approached significance, $t(3)=2.36, p<.15$ (all other $t$ s $<$ 1 ) in stable contexts. For watching TV, only self-concept predicted future behavior $(p<.001)$ in unstable contexts, and only past behavior was a significant predictor $(p<.05)$ in stable contexts.
} 
Table 8

Bivariate Correlations for Prediction of Recycling in Ouellette (1996)

\begin{tabular}{|c|c|c|c|c|c|c|c|c|}
\hline Variable & Future & Past & Intent & Attitude & $\begin{array}{c}\text { Subjective } \\
\text { norm }\end{array}$ & $\begin{array}{l}\text { Perceived } \\
\text { control }\end{array}$ & $\begin{array}{c}\text { Attitude } \\
\text { accessibility }\end{array}$ & Self \\
\hline Future & 一 & $.96^{* *}$ & .48 & .28 & .39 & -.45 & -.28 & .47 \\
\hline Past & .12 & - & .50 & .33 & .43 & -.42 & -.18 & .42 \\
\hline Intent & $.43 * *$ & $.40 * *$ & - & .47 & .63 & $-.70^{*}$ & .16 & $.81 * *$ \\
\hline Attitude & .10 & .13 & $.32^{* *}$ & $\longrightarrow$ & -.18 & -.04 & -.19 & .25 \\
\hline Subjective norm & $.33 * *$ & .14 & $.44 * *$ & $.41 * *$ & - & -.58 & .53 & .56 \\
\hline Perceived control & $-.43^{* *}$ & $-.39 * *$ & $-.71 * *$ & $-.28 * *$ & $-.32 * *$ & - & .02 & $-.92 * *$ \\
\hline Accessibility & -.11 & -.08 & $-.33 * *$ & $-.32 * *$ & -.17 & $.29 * *$ & - & -.14 \\
\hline Self & $.39 * *$ & $.45^{* *}$ & $.64 * *$ & .15 & $.34 * *$ & $-.73 * *$ & -.13 & - \\
\hline
\end{tabular}

Note. Future $=$ future behavior; Past $=$ past behavior; Self $=$ self-concept. Variables were scored so that higher numbers represent more frequent future behavior, more frequent past behavior, stronger intentions to perform the behavior, more favorable attitudes, more favorable perceived norms, greater perceived difficulty performing the behavior, lesser accessibility of attitudes, and a self-concept as a performer of the behavior. Coefficients above the diagonal represent behavior performed in stable contexts $(n=9)$, and coefficients below the diagonal represent behavior performed in unstable contexts $(n=89)$.

${ }^{*} p<.05 . \quad{ }^{* *} p<.01$.

\section{Past Behavior as an Indicator of Habit}

Frequency of past behavior will not always be a good indicator of habit. When supporting contexts shift or when behavior is difficult or not performed on a daily or weekly basis, past

Table 9

Regression Models Predicting Frequency of Future Television Watching ( $N=72$; Ouellette, 1996)

\begin{tabular}{rllll}
\hline Predictor & $b$ & $t$ & $p$ \\
\hline
\end{tabular}

Full model

\begin{tabular}{lrrr} 
Intention & 0.02 & 0.01 & \\
Past behavior & 0.08 & 0.86 & \\
Context & 1.49 & 0.98 & \\
Perceived control & 0.63 & 0.84 & \\
Attitude accessibility & 10.52 & 1.03 & \\
Self-concept & 1.84 & 3.53 & .001 \\
Intention $\times$ Context & 0.98 & 0.81 & \\
Past Behavior $\times$ Context & 0.36 & 2.43 & .02 \\
Attitude Accessibility $\times$ Context & -8.21 & -0.53 & \\
Perceived Control $\times$ Context & 0.84 & 0.69 & \\
Self-Concept $\times$ Context & -1.80 & -2.40 & .02 \\
\hline
\end{tabular}

Impact of predictors within unstable contexts $(N=39)^{\mathrm{a}}$

\begin{tabular}{|c|c|c|c|}
\hline Intention & 0.90 & 1.06 & \\
\hline Past behavior & 0.04 & 0.48 & \\
\hline Perceived control & 0.39 & 0.56 & \\
\hline Attitude accessibility & 7.98 & 0.83 & \\
\hline Self-concept & 1.87 & 3.74 & .001 \\
\hline \multicolumn{4}{|c|}{ Impact of predictors within stable contexts $(N=33)^{\mathrm{a}}$} \\
\hline Intention & 1.56 & 1.83 & .08 \\
\hline Past behavior & 0.40 & 3.27 & .01 \\
\hline Perceived control & 1.74 & 1.81 & .08 \\
\hline Attitude accessibility & 4.08 & 0.33 & \\
\hline Self-concept & 0.09 & 0.17 & \\
\hline
\end{tabular}

Note. All variables are centered except the categorical predictor of context. $b=$ unstandardized $b$.

${ }^{a}$ Simple effects decomposition. behavior is unlikely to reflect habit. These limitations might justify alternate measures of habit strength. For example, respondents have been asked to distinguish between past act frequency that reflects habits and past-act frequency that may reflect other factors. That is, respondents have been asked how

Table 10

Regression Models Predicting Frequency of Future Recycling $(N=99 ;$ Ouellette, 1996)

\begin{tabular}{rrrr}
\hline Predictor & $b$ & $t$ & $p$ \\
\hline
\end{tabular}

Full model

Intention

Past behavior

Context

Perceived control

Attitude accessibility

Self-concept

Intention $\times$ Context

Past Behavior $x$ Context

Attitude Accessibility $\times$ Context

Perceived Control $\times$ Context

Self-Concept $\times$ Context

$\begin{array}{rr}0.46 & 1.51 \\ -0.15 & -0.79 \\ -1.84 & -0.47 \\ -0.40 & -1.20 \\ 2.50 & 0.41 \\ 0.27 & 0.94 \\ -0.80 & -0.38 \\ 0.68 & 2.08 \\ -13.21 & -0.29 \\ 0.57 & 0.27 \\ 0.19 & 0.09\end{array}$

Impact of predictors within unstable contexts $(N=90)^{\mathrm{a}}$

\begin{tabular}{lrrr} 
Intention & 0.47 & 1.81 & .07 \\
Past behavior & -0.16 & -1.08 & \\
Perceived control & -0.40 & -1.20 \\
Attitude accessibility & 2.50 & 0.40 \\
Self-concept & 0.26 & 0.94 \\
\hline
\end{tabular}

Impact of predictors within stable contexts $(N=9)^{\mathrm{a}}$

\begin{tabular}{lrrr} 
Intention & -0.33 & -0.25 & \\
Past behavior & 0.50 & 4.90 & .02 \\
Perceived control & 0.17 & 0.12 & \\
Attitude accessibility & -10.67 & -0.36 & \\
Self-concept & 0.45 & 0.32 & \\
\hline
\end{tabular}

Note. All variables are centered except the categorical predictor of context. $b=$ unstandardized $b$.

- Simple effects decomposition. 
often they engage in a target behavior and whether they do so "by force of habit" or "without awareness" (e.g., Mittal, 1988; Towler \& Shepherd, 1992; Wittenbraker, Gibbs, \& Kahle, 1983). We are skeptical, however, that people can accurately answer questions that require them to distinguish between behaviors that are generated through automatic mechanisms and behaviors that reflect conscious decision making. Alternately, Verplanken, Aarts, van Knippenberg, and van Knippenberg (1994) assessed transportation habits from people's estimates of how they would perform everyday trips mentioned in a series of scenarios (e.g., going to the supermarket). Although this measure proved to be moderately correlated with the standard assessment of past act frequency ( $r$ s ranged from .31 to .42 ), it yielded unique effects on information acquisition that were not demonstrated by the past-behavior measure. Thus, scenario estimates appear to have information-processing implications that are not found with estimates of frequency of past behavior. It may be that these reflect behavioral scripts (Schank \& Abelson, 1977) as well as habit. At least in contexts conducive to habit formation and performance, then, past behavior may be the best indicator of habit strength.

The validity of past behavior as an indicator of habit depends importantly on how accurately people can report on their past acts. Reports of act frequency are likely to be more accurate with rating scales that assess numbers of acts than with scales that use adjectives to reflect frequency (e.g., often, sometimes, rarely). Adjective estimates are ambiguous, and their meaning varies with a given behavioral domain. In domains with low rates of occurrence in daily life, such as donating blood, respondents could claim frequent performance with only two or three instances of the behavior in a year. Alternately, in domains with high rates of occurrence, such as drinking coffee, respondents could claim seldom or infrequent performance for engaging in the behavior once a week. In addition, rating scales that tap respondents' estimates of the rate at which they perform a behavior, such as the typical number of times per week one eats breakfast, are often easier to complete and may be more accurate than scales that encourage enumeration of specific instances, such as recalling each instance of breakfast in the past 2 weeks (Blair \& Burton, 1987; Menon, 1993). Because respondents will have forgotten many specific instances, enumeration can lead to underreports of behavior frequency. Accuracy of behayioral reports also depends on the inference rules that respondents use to generalize from their recall of specific episodes or occurrence rates (Schwarz, 1990). Questions that emphasize the use of accurate rules (e.g., raising the possibility of changes in frequency of performance across the estimation period) are most likely to yield valid estimates of past behavior.

Further precision in the measurement of habit may be gained by considering the goals that have motivated past behavior. For example, Aarts and Dijksterhuis (1997) activated a number of everyday transportation goals (e.g., going shopping) for people who in the past had frequently used a bicycle to meet those goals. These people easily and quickly decided what mode of transportation to use when presented with relevant situational cues (e.g., grocery store). However, when the transportation goals were not made salient, people's responses were no faster to the situational cues than responses of people who did not have a habit of bicycle use. It seems, then, that cognitive repre- sentations of the links between behavior and context were activated only with relevant goals. Especially for behaviors that can serve multiple goals, it may be useful in future work to assess habits while the particular goal that has directed past behavior is salient (see also Aarts, Paulussen, \& Schaalma, 1997).

\section{Conclusion}

The present review was designed to integrate habit into contemporary approaches to the prediction of social behavior by demonstrating its empirical independence from other predictors and by explaining how its impact derives from the cognitive processes and goal specification associated with well-practiced behaviors in constant contexts.

Theoretical understanding of habits has practical use; it enables social scientists to devise more effective strategies to help people initiate new behavior and change existing behavior. Altering frequently performed behavior in constant contexts requires conscious decision making to devise and implement new responses and to suppress or divert any well-practiced behavior that might be cued by the environment (e.g., sidetracking; see Guthrie, 1935; James, 1890). Specifically, effective change strategies are likely to include the formulation of explicit plans to initiate and implement a new behavior (Gollwitzer, 1996). If the new behavior then accomplishes one's current goals without impeding other valued outcomes, conscious intentions to initiate and perform the new response are likely to remain strong.

A potential point of failure in implementing behavior change decisions arises when the behavior has long-term rather than short-term rewards (Aarts, Paulussen, \& Schaalma, 1997). For example, people may be convinced that they should adopt a healthier lifestyle, but when they formulate and then implement plans to do so, they experience little immediate evidence that the new responses (e.g., increasing exercise, following a lowfat diet) enhance well being. In addition to experiencing uncertainty and apprehension about how to perform the new behaviors (outcomes likely with any shift in response), the healthy behavjors themselves may, in the short run, appear to diminish enjoyment in life. Given the lack of immediate evidence that the new responses will yield positive outcomes, many people will not persist. They will not exert deliberate control of performance details until the new behavior is established with sufficient strength to proceed automatically without conscious awareness of intent and to reveal its long-term benefits. Old habits are then likely to be maintained because of the speed and ease with which past patterns of behavior can be initiated and executed, because the old behaviors are cued by prevailing environmental events, and because these patterns are not inconsistent with short-term goals.

The most effective change strategies are likely to be ones that impede performance of established behavior while facilitating formation of new behaviors into habits. For cxample, shifts in the supporting environment can derail the automatic cueing and execution of old habits and increase the importance of conscious intentions. To maintain intentions to adopt a healthier lifestyle, change strategies should ensure that some immediate, positive consequences emerge from the new healthy behavior. In addition, effective strategies should provide the opportunity for repetition of the new behavior in a stable supporting environment. 
Frequent performance of the desired behavior in such contexts is especially likely to yield new habits that can themselves proceed relatively automatically.

\section{References}

References marked with an asterisk indicate studies included in the meta-analysis.

Aarts, H., \& Dijksterhuis, A. (1997). Contingencies between situations and behavior: Goal-directed automaticity in habits. Unpublished manuscript, Eindhoven University of Technology, Eindhoven, The Netherlands.

Aarts, H., Paulussen, T., \& Schaalma, H. (1997). Physical exercise habit: On the conceptualization and formation of habitual health behaviours. Health Education Research: Theory and Practice, 12, 363-374.

Abelson, R. P. (1981). Psychological status of the script concept. American Psychologist, 36, 715-729.

Aiken, L. S., \& West, S. G. (1991). Multiple regression: Testing and interpreting interactions. Newbury Park, CA: Sage.

Ajzen, I. (1985). From intentions to actions: A theory of planned behavior. In J. Kuhi \& J. Beckmann (Eds.), Action control (pp. 11-39). Berlin: Springer-Verlag.

Ajzen, I. (1987). Attitudes, traits, and actions: Dispositional prediction of behavior in personality and social psychology. In L. Berkowitz (Ed.), Advances in experimental social psychology (Vol. 20, pp. 163). San Diego, CA: Academic Press.

Ajzen, I. (1991). The theory of planned behavior. Organizational Behavior and Human Decision Processes, 50, 179-211.

Ajzen, I. (1996). The theory of planned behavior: A bibliography. Unpublished manuscript, University of Massachusetts at Amherst.

Ajzen, I., \& Fishbein, M. (1977). Attitude-behavior relations: A theoretical analysis and review of empirical research. Psychological Bulletin, 84, 888-918.

Allport, F. H. (1924). Social psychology. Boston: Houghton Mifflin.

Allport, G. W. (1935). Attitudes. In C. Murchison (Ed.), Handbook of social psychology (pp. 798-844). Worcester, MA: Clark University Press.

*Bagozzi, R. P. (1981a). Attitudes, intentions, and behavior: A test of some key hypotheses. Journal of Personality and Social Psychology, 41, 607-627.

*Bagozzi, R. P. ( 1981 b). An examination of the validity of two models of attitude. Multivariate Behavioral Research, 16, 323-359.

*Bagozzi, R. P., Baumgartner, H., \& Yi, Y. (1992). State versus action orientation and the theory of reasoned action: An application to coupon usage. Joumal of Consumer Research, 18, 505-518.

*Bagozzi, R. P., \& Warshaw, P. R. (1990). Trying to consume. Journal of Consumer Research, 17, 127-140.

*Bagozzi, R. P., \& Warshaw, P. R. (1992). An examination of the etiology of the attitude-behavior relation for goal-directed behaviors. Multivariate Behavioral Research, 27, 601-634.

Bandura, A. (1986). Social foundations of thought and action. Englewood Cliffs, NJ: Prentice Hall.

Bargh, J. A. (1989). Conditional automaticity: Varieties of automatic influence in social perception and cognition. In J. S. Uleman \& J. A. Bargh (Eds.), Unintended thought (pp. 3-51). New York: Guilford Press.

Bargh, J. A. (1994). The four horsemen of autonaticity: Awareness, intention, efficiency, and control in social cognition. In R. S. Wyer, J., \& T. K. Srull (Eds.), Handbook of social cognition (Vol. 1, 2nd ed., pp. 1-40). Hillsdale, NJ: Erlbaum.

Bargh, J. A., \& Barndollar, K. (1996). Automaticity in action: The unconscious as repository of chronic goals and motives. In P. M. Gollwitzer \& J. A. Bargh (Eds.), The psychology of action: Linking cogni- tion and motivation to behavior (pp. 457-481). New York: Guilford Press.

Bargh, J. A., Chaiken, S., Grovender, R., \& Pratto, F. (1992). The generality of the automatic attitude activation effect. Journal of Personality and Social Psychology, 62, 893-912.

Bargh, J. A., \& Gollwitzer, P. M. (1994). Environmental control of goal-directed action: Automatic and strategic contingencies between situations and behavior. In M.P. Zanna (Ed.), Nebraska Symposium on Motivation: Integrative views of motivation, cognition, and emotion (Vol. 41, pp. 71-124). Lincoln: University of Nebraska Press.

*Beck, L., \& Ajzen, I. (1991). Predicting dishonest aclions using the theory of planned behavior. Journal of Research in Personality, 25, 285-301.

Becker, B. J. ( 1992). Using results from replicated studies to estimate linear models. Journal of Educational Statistics, 17, 341-362.

Becker, B. J., \& Schram, C. M. (1994). Examining explanatory models through research synthesis. In H. Cooper \& L. V. Hedges (Eds.), The handbook of research synthesis (pp. 357-381). New York: Russell Sage Foundation.

Bem, D. J. (1972). Self-perception theory. In L. Berkowitz (Ed.), Advances in experimental social psychology (Vol. 6, pp. 1-62). San Diego, CA: Academic Press.

*Bentler, P. M., \& Speckart, G. (1979). Models of attitude-behavior relations. Psychological Review, 86, 452-464.

*Bentler, P. M., \& Speckart, G. (1981). Attitudes "cause"' behaviors: A structural equation analysis. Journal of Personulity and Social Psychology, 40, 226-238.

Blair, E., \& Burton, S. (1987). Cognitive processes used by survey respondents to answer behavioral frequency questions. Journal of Cunsumer Research, 14, 280-288.

*Boyd, B., \& Wandersman, A. (1991). Predicting undergraduate condom use with the Fishbein and Ajzen and the Triandis attitude-behavior models: Implications for public health interventions. Journal of Applied Social Psychology, 21, 1810-1830.

*Brinberg, D. (1979a). The comparison of three attitude models for the prediction of blood donation behavior (Doctoral dissertation, University of Illinois at Urbana-Champaign, 1979). Dissertation Abstracts International, 40, AAC 8004141.

*Brinberg, D. ( 1979b). An examination of the determinants of intention and behavior: A comparison of two models. Journal of Applied Social Psychology, 9, 560-575.

*Brinberg, D., \& Durand, J. (1983). Eating at fast food restaurants: An analysis using two behavioral intentions models. Journal of Applied Social Psychology, 13, 459-472.

*Budd, R. J., North, D., \& Spencer, C. (1984). Understanding seat-belt use: A test of Bentler and Speckart's extension of the "theory of reasoned action." European Journal of Social Psychology, 14, 6978.

*Budd, R. J., \& Spencer, C. (1985). Exploring the role of personal normative beliefs in the theory of reasoned action: The problem of discriminating between alternative path models. European Journal of Social Psychology, 15, 299-313.

Bushman, B. J. (1994). Vote-counting procedures in meta-analysis. In H. Cooper \& L. V. Hedges (Eds.), The handbook of research synthesis (pp. 193-213). New York: Russell Sage Foundation.

Carver, C. S., \& Scheier, M. F. (1990). Principles of self-regulation: Action and emotion. In E. T. Higgins \& R. M. Sorrentino (Eds.), Handbook of motivation and cognition: Foundations of social behavior (Vol. 2, pp. 3-52). New York: Guilford Press.

*Charng, H., Piliavin, J. A., \& Callero, P. L. (1988). Role identity and reasoned action in the prediction of repeated behavior. Social Psychology Quarterly, 51, 303-317.

Cohen, J., \& Cohen, P. (1983). Applied multiple regression/currelation analysis for the behavioral sciences ( 2 nd ed.). Hillsdale, NJ: Erlbaum. 
Croll, K. (1983). An investigation of the relationship between attitude of nurses toward professionalization and participation in continuing education activities (Doctoral dissertation, Florida State University, 1983). Dissertation Abstracts International, 44, AAC 8324917.

*Crosby, L. A., \& Muehling, D. D. (1983). External variables and the Fishbein model: Mediation, moderation, or direct effects? In R.P. Bagozzi \& A. M. Tybout (Eds.), Advances in consumer research (Vol. 10, pp. 94-99). Ann Arbor, MI: Association for Consumer Research. *Dubanoski, J. P. (1987). Preventive health behavior: A model of adherence prediction. Unpublished doctoral dissertation, University of Hawaii.

Durkheim, E. (1964). The division of labor in society (G. Simpson, Trans.). New York: Free Press. (Original work published 1902)

Eagly, A. H., \& Chaiken, S. (1993). The psychology of attitudes. San Diego, CA: Harcourt Brace Jovanovich.

*East, R. (1993). Investment decisions and the theory of planned behaviour. Journal of Economic Psychology, 14, 337-375.

*Echebarria, A., Paez, D., \& Valencia, J. F. (1988). Testing Ajzen and Fishbein's attitudes model: The prediction of yoting. European Journal of Social Psychology, 18, 181-189.

*Erdahl, P. C. (1990). The threat of nuclear war: A structural analysis of attitudinal and behavioral responses (Doctoral dissertation, State University of New York at Buffalo, 1990). Dissertation Abstracts International, 51, AAC 9033696.

Fazio, R. H. (1990). Multiple processes by which attitudes guide behayior: The MODE model as an integrative framework. In W. D. Spaulding (Ed.), Advances in experimental social psychology (Vol. 23, pp. 74-109). San Diego, CA: Academic Press.

Fazio, R. H., Chen, J., McDonel, E. C., \& Sherman, S. J. (1982). Attitude accessibility, attitude-behavior consistency, and the strength of the object-evaluation association. Journal of Experimental Social Psychology, 18, 339-357.

*Feldman, R. H. L., \& Mayhew, P. C. (1984). Predicting nutrition behavior: The utilization of a social psychological model of health behavior. Basic and Applied Social Psychology, 5, 183-195.

Festinger, L. (1957). A theory of cognitive dissonance. Evanston, IL: Row, Peterson.

Fishbein, M., \& Ajzen, I. (1975). Belief, attitude, intention and behavior: An introduction to theory and research. Reading, MA: AddisonWesley.

Fishbein, M., \& Ajzen, I. (1995). Research based on the theory of reasoned action: A bibliography. Unpublished manuscript, University of Illinois at Urbana-Champaign.

*Fredricks, A. J., \& Dossett, D. L. (1983). Attitude-behavior relations: A comparison of the Fishbein-Ajzen and the Bentler-Speckart models. Journal of Personality and Social Psychology, 45, 501-512.

*Godin, G. (1983). Psycho-social factors influencing intentions to exercise of young students. Dissertation Abstracts International, 45,2A (University Microfilms No. 62275)

*Godin, G., Colantonio, A., Davis, G. M., Shephard, R. J., \& Simard, C. (1986). Prediction of leisure time exercise behavior among a group of lower-limb disabled adults. Journal of Clinical Psychology, 42, 272-279

*Godin, G., Cox, M. H., \& Shephard, R. J. (1983). The impact of physical fitness evaluation on behavioural intentions towards regular exercise. Canadian Journal of Applied Sport Science, 8, 240-245.

*Godin, G., \& Gionet, N. J. (1991). Determinants of an intention to exercise of an electric power commission's employees. Ergonomics, $34,1221-1230$.

${ }^{*}$ Godin, G., \& Shephard, R. J. (1985). Psycho-social predictors of exercise intentions among spouses. Canadian Journal of Applied Sport Science, 10, 36-43.

*Godin, G., \& Shephard, R. J. (1986a). Importance of type of attitude to the study of exercise-behavior. Psychological Reports, 58, 9911000 .

*Godin, G., \& Shephard, R. J. (1986b). Psychosocial factors influencing intentions to exercise of young students from grades 7 to 9. Research Quarterly for Exercise and Sport, 57, 41-52.

*Godin, G., \& Shephard, R. J. (1987). Psychosocial factors influencing intentions to exercise in a group of individuals ranging from 45 to 74 years of age. In M. E. Berridge \& G. R. Wald (Eds.), International perspectives on adapted physical activity (pp. 243-249). Champaign, IL: Human Kinetics Publications.

*Godin, G., Valois, P., Jobin, J., \& Ross, A. (1991). Prediction of intention to exercise of individuals who have suffered from coronary heart disease. Journal of Clinical Psychology, 47, 762-772.

*Godin, G., Valois, P., \& Lepage, L. (1993). The pattern of influence of perceived behavioral control upon exercising behavior: An application of Ajzen's theory of planned behavior. Journal of Behavioral Medicine, 16, 81-102.

*Godin, G., Valois, P., Shephard, R. J., \& Desharnais, R. (1987). Prediction of leisure-time exercise behavior: A path analysis (LISREL V) model. Journal of Behavioral Medicine, 10, 145-158.

*Godin, G., Vezina, L., \& Leclerc, O. (1989). Factors influencing intentions of pregnant women to exercise after giving birth. Public Health Reports, 104, 188-195.

Gollwitzer, P. M. (1996). The volitional benefits of planning. In P. M. Gollwitzer \& J. A. Bargh (Eds.), The psychology of action: Linking cognition and motivation to behavior (pp. 287-312). New York: Guilford Press.

Guthrie, E. R. (1935). The psychology of learning. New York: Harper. Hay, J. F., \& Jacoby, L. L. (1996). Separating habit and recollection: Memory slips, process dissociations, and probability matching. Journal of Experimental Psychology: Learning, Memory, and Cognition, $22,1323-1335$.

Heckhausen, H., \& Beckmann, J. (1990). Intentional action and action slips. Psychological Review, 97, 36-48.

Hedges, L. V., \& Olkin, I. (1985). Statistical methods for meta-analysis. San Diego, CA: Academic Press.

Heuer, H., \& Schmidt, R. A. (1988). Transfer of learning among motor patterns with different relative timing. Journal of Experimental Psychology: Human Perception and Performance, 14, 241-252.

*Hill, D., Gardner, G., \& Rassaby, J. (1985). Factors predisposing women to take precautions against breast and cervix cancer. Journal of Applied Social Psychology, 15, 59-79.

*Hughes, R. A. (1984). The interrelationship of attitude and past experience in the prediction of volunteer and donating behavior (Doctoral dissertation, Catholic University of America, 1984). Dissertation Abstracts International, 45. AAC 8416048.

Hull, C. L. (1943). Principles of behavior: An intraduction to behavior theory. New York: Appleton-Century-Crofts.

Hunt, W. A., Matarazzo, J. D., Weiss, S. M., \& Gentry, W. D. (1979). Associative learning, habit, and health behavior. Journal of Behavioral Medicine, 2, 111-124.

James, W. (1890). The principles of psychology. New York: Holt

*Jemmott, L. S., \& Jemmott, J. B., III. (1991). Applying the theory of reasoned action to AIDS risk behavior: Condom use among black women. Nursing Research, 40, 228-234.

*Kahle, L. R., \& Beatty, S. E. (1987a). Cognitive consequences of legislating postpurchase behavior: Growing up with the bottle bill. Journal of Applied Social Psychology, 17, 828-843.

*Kahle, L. R., \& Beatty, S. E. (1987b). The task situation and habit in the attitude-behavior relationship: A social adaptation view. Journal of Social Behavior and Personality, 2, 219-232.

*Kashima, Y., Gallois, C., \& McCamish, M. (1992). Predicting the use of condoms: Past behavior, norms, and the sexual partner. In T. Edgar, 
M. A. Fitzpatrick, \& V. S. Freimuth (Eds.), AIDS, a communication perspective (pp. 21-46). Hillsdale, NJ: Erlbaum.

*Kashima, Y., Gallois, C., \& McCamish, M. (1993). The theory of reasoned action and cooperative behaviour: It takes two to use a condom. British Journal of Social Psychology, 32, 227-239.

Kilty, K. M., \& Behling, J. H. (1985). Predicting the retirement intentions and attitudes of professional workers. Journal of Gerontology, 40, 219-227.

Kraus, S. J. ( 1995). Attitudes and the prediction of behavior: A metaanalysis of the empirical literature. Personality and Social Psychology Bulletin, 21, 58-75.

*Lacy, W. B. (1981). The influence of attitudes and current friends on drug use intentions. The Journal of Social Psychology, 113, 65-76.

Landis, D., Triandis, H. C., \& Adamopoulos, J. (1978). Habit and behavioral intentions as predictors of social behavior. Joumal of Social Psychology, 106, 227-237.

Langer, E. J. (1989a). Mindfulness. Reading, MA: Addison-Wesley.

Langer, E. J. (1989b) . Minding matters: The consequences of mindlessness-mindfulness. In L. Berkowitz (Ed.), Advances in experimental social psychology (Vol. 22, pp. 137-173). Orlando, FL: Academic Press.

*Lauver, D., \& Chang, A. (1991). Testing theoretical explanations of intention to seek care for a breast cancer symptom. Journal of Applied Social Psychology, 21, 1440-1458.

*Lockhart, D. C. (1986). Mailed questionnaire returning behavior: A comparison of Triandis' and Fishbein's theories of the predictors (Doctoral dissertation, Southern Illinois University at Carbondale, 1986). Dissertation Abstracts International, 47, AAC 8622995.

Logan, G. D. (1989). Automaticity and cognitive control. In J. S. Uleman \& J. A. Bargh (Eds.), Unintended thought (pp. 52-74). New York: Guilford Press.

Logan, G. D., \& Cowan, W. B. (1984). On the ability to inhibit thought and action: A theory of an act of control. Psychological Review, 91, 295-327.

*Macy, S. M., \& Brown, M. A. (1983). Residential energy conservation: The role of past experience in repetitive household behavior. Environment and Behavior, 15, 123-141.

*Mandel, F. S. (1986). A comparison of two models used in the prediction and explanation of behavior (Doctoral dissertation, Columbia University, 1986). Dissertation Abstracts International. 47, AAC 8623567.

*Manstead, A. S. R., Proffitt, C., \& Smart, J. L. (1983). Predicting and understanding mothers' infant-feeding intentions and behavior: Testing the theory of reasoned action. Journal of Personality and Social Psychology, 44, 657-671.

Mead, G. H. (1936). Movements of thought in the nineteenth century. Chicago: University of Chicago Press.

Menon, G. (1993). The effects of accessibility of information in memory on judgments of behavioral frequencies. Journal of Consumer Research, 20, 431-440.

Miller, N. E., \& Dollard, J. (1941). Social learning and imitation. New Haven, CT: Yale University Press.

*Mittal, B. (1988). Achieving higher seat belt usage: The role of habit in bridging the attitude-behavior gap. Journal of Applied Social Psychology, 18, 993-1016.

*Montano, D. E. (1986). Predicting and understanding influenza vaccination behavior: Alternatives to the health belief model. Medical Care, $24,438-453$.

*Montano, D. E., \& Taplin, S. H. (1991). A test of an expanded theory of reasoned action to predict mammography participation. Social Science and Medicine, 32, 733-741.

*Mullen, P. D., Hersey, J. C., \& Iverson, D. C. (1987). Health behavior models compared. Social Science and Medicine, 24, 973-981.

Norman, P., \& Conner, M. (1996). The role of social cognition models in predicting health behaviours: Future directions. In M. Conner \& $\mathrm{P}$. Norman (Eds.), Predicting health behaviour: Research and practice with social cognition models (pp. 197-225). Buckingham, England: Open University Press.

*Onyedika, I. S. (1983). Two models of social behavior in accounting for maternal intentionality and behavior (Doctoral dissertation, University of Pittsburgh, 1983). Dissertation Abstracts International, 44 AAC 8327626.

Ouellette, J. A. (1996). How to measure habit? Subjective experience and past behavior. Unpublished doctoral dissertation, Texas A\&M University, College Station.

Pashler, H. (1994). Dual-task interference in simple tasks: Data and theory. Psychological Bulletin, 116, 220-244.

Petty, R. E., \& Krosnick, J. A. (1995). Attitude strength: Antecedents and consequences. Mahwah, $\mathrm{NJ}$ : Erlbaum.

*Pomazal, R. J. (1974). Attitudes, normative beliefs, and altruism: Help for helping behavior (Doctoral dissertation, University of Illinois at Urbana-Champaign, 1974). Dissertation Abstracts International, 35, AAC 7511822.

Posner, M. I., \& Rothbart, M. K. (1989). Intentional chapters of unintended thoughts. In J. S. Uleman \& J. A. Bargh (Eds.), Unintended thought (pp. 450-469). New York: Guilford Press.

Posner, M. I., \& Snyder, C. R. (1975). Facilitation and inhibition in the processing of signals. In P. M. A. Rabbit \& S. Dornic (Eds.), Attention and performance V (pp. 669-681). London: Academic Press.

Proctor, R. W., \& Dutta, A. (1993). Do the same stimulus-response relations influence choice reactions initially and after practice? Jour nal of Experimental Psychology: Learning, Memory, and Cognition. 19, 922-930.

*Quinn, E. B. (1987). Psychosocial determinants of breastfeeding and the intake of dietary calcium in pregnancy. Unpublished doctoral dissertation, University of Maryland College Park.

Ronis, D. L., Yates, J. F., \& Kirscht, J. P. (1989). Attitudes, decisions, and habits as determinants of repeated behavior. In A. R. Pratkanis, S. J. Brecklet, \& A. G. Greenwald (Eds.), Attitude structure and function (pp. 213-239). Hillsdale, NJ: Erlbaum.

Rosenthal, R. (1991). Meta-analytic procedures for social research. Newbury Park, CA: Sage.

*Rutter, D. R., \& Bunce, D. J. (1989). The theory of reasoned action of Fishbein and Ajzen: A test of Towriss's amended procedure for measuring beliefs. British Journal of Social Psychology, 28, 39-46.

SAS PROC IML (Version 6.06) [Computer software]. (1989). Cary, NC: SAS Institute, Inc.

Schank, R. C., \& Abelson, R. P. (1977). Scripts, plans, goals and understanding: An inquiry into human knowledge structures. Hillsdale, $\mathrm{NJ}$ Erlbaum.

Schneider, W., \& Shiffrin, R. M. (1977). Controlled and automatic human information processing: I. Detection, search, and attention. Psychological Review, 84, 1-66.

Schwarz, N. (1990). Assessing frequency reports of mundane behaviors: Contributions of cognitive psychology to questionnaire construction In C. Hendrick \& M. S. Clark (Eds.), Review of personality and social psychology: Research methods in personality and social psychology (Vol. 11, pp. 98-119). Newbury Park, CA: Sage.

Sheppard, B. H., Hartwick, J., \& Warshaw, P. R. (1988). The theory of reasoned action: A meta-analysis of past research with recommendations for modifications and future research. Journal of Consumer Research, 15, 325-343.

Shiffrin, R. M., \& Schneider, W. (1977). Controlled and automatic human information processing: II. Perceptual learning, automatic attending, and a general theory. Psychological Review, 84, 127-190.

Snedecor, G. W., \& Cochran, W. G. (1967). Statistical methods (6th ed.). Ames: lowa State University Press.

Staats, A. W. (1965). Verbal habit-Families, concepts, and the operant 
conditioning of word classes. In R. C. Anderson \& D. P. Ausubel (Eds.), Readings in the psychology of cognition (pp. 18 40). New York: Holt, Rinehart, \& Winston.

Sutton, S. (1994). The past predicts the future: Interpreting behaviourbehaviour relationships in social psychological models of health behaviour. In D. R. Rutter \& L. Quine (Eds.), Social psychology and health: European perspectives (pp. 71-88). Aldershot, England: Avebury Press.

*Theodorakis, Y. (1992). Prediction of athletic participation: A test of planned behavior theory. Percepinal and Motor Skills, 74, 371-379.

*Theodorakis, Y., Doganis, G., Bagiatis, K., \& Gouthas, M. (1991). Preliminary study of the ability of reasoned action model in predicting exercise behavior of young children. Perceptual and Motor Skills, 72, 51-58.

*Towler, G., \& Shepherd, R. (1992). Modification of Fishbein and Ajzen's theory of reasoned action to predict chip consumption. Food Quality and Preference, 3, 37-45.

Triandis, H. C. (1977). Interpersonal behavior. Monterey, CA: Brooks/ Cole.

Triandis, H. C. (1980). Values, attitudes, and interpersonal behavior. In H. E. Howe, Jr. \& M. M. Page (Eds.), Nebraska Symposium on Motivation: Beliefs, attitudes, and values, 1979 (Vol. 27, pp. 195259). Lincoln: University of Nebraska Press.

Vallacher, R. R., \& Kaufman, J. (1996). Dynamics of action identification: Volatility and structure in the mental representation of behavior. In P. M. Gollwitzer \& J. A. Bargh (Eds.), The psychology of action: Linking cognition and motivation to behavior (pp. 260-282). New York: Guilford Press.

Vallacher, R. R., \& Wegner, D. M. (1987). What do people think they're doing: Action identification and human behavior. Psychological Review; 94, 3-15.

*Valois, P., Desharnais, R., \& Godin, G. (1988). A comparison of the Fishbein and Ajzen and the Triandis attitudinal models for the prediction of exercise intention and behavior. Journal of Behavioral Medicine, $11,459-472$.

Valois, P., Shephard, R. J., \& Godin, G. (1986). Relationship of habit and perceived physical ability to exercise-behavior. Perceptual and Motor Skills, 62, 811-817.

van den Putte, S. J. H. M. (1993). On the theory of reasoned action. Unpublished doctoral dissertation, University of Amsterdam.

Vera, A. H., \& Simon, H. A. (1993). Situated action: A symbolic interpretation. Cognitive Science, 17, 7-48.

Verplanken, B., Aarts, H., van Knippenberg, A., \& van Knippenberg, C. (1994). Attitude versus general habit: Antecedents of travel mode choice. Journal of Applied Social Psychology, 24, 285-300.

Warshaw, P. R., \& Davis, F. O. (1985). Disentangling behavioral intention and behavioral expectation. Journal of Experimental Social Psychology, 21, 213-228.

Watson, J. B. (1919). Psychology from the standpoint of a behaviorist. Philadelphia: Lippincott.

Weber, M. (1946). The social psychology of the world religions. In H. H. Gerth \& C. W. Mills (Eds.), From Max Weber: Essays in sociology (pp. 267-301). New York: Oxford University Press. (Original work published 1915)

Wegner, D. M. (1992). You can't always think what you want: Problems in the suppression of unwanted thoughts. In M. P. Zanna (Ed.), Advances in experimental social psychology (Vol. 25, pp. 193-225). San Diego, CA: Academic Press.

Wegner, D. M., \& Bargh, J. A. (1998). Control and automaticity in social life. In D. Gilbert, S. T. Fiske, \& G. Lindzey (Eds.), Handbook of social psychology (4th ed., pp. 446-496). New York: McGrawHill.

*Wittenbraker, J., Gibbs, B. L., \& Kahle, L. R. (1983). Seat belt attitudes, habits, and behaviors: An adaptive amendment to the Fishbein model. Journal of Applied Social Psychology, 13, 406-421.

Zimmerman, R. S. (1983). Preventive health attitudes and behaviors: A test of three models (Doctoral dissertation, University of Wisconsin-Madison, 1983). Dissertation Abstracts International, 44, AAC 8321782 .

Received August 29, 1996

Revision received December 15, 1997

Accepted January 23, 1998 